\title{
Stability, safety, and transcorneal mechanistic studies of ophthalmic lyophilized cyclosporine- loaded polymeric micelles
}

This article was published in the following Dove Press journal: International Journal of Nanomedicine

\author{
Yan Shen ${ }^{1, *}$ \\ Yinglan $\mathrm{Yu}^{1, *}$ \\ Birendra Chaurasiya' \\ Xiaolian $\mathrm{Li}^{\prime}$ \\ Ying $\mathrm{Xu}^{2}$ \\ Thomas J Webster ${ }^{3}$ \\ Jiasheng Tu' \\ Runing Sun ${ }^{4}$ \\ 'Department of Pharmaceutics, \\ Center for Research Development \\ and Evaluation of Pharmaceutical \\ Excipients and Generic Drugs, School \\ of Pharmacy, China Pharmaceutical \\ University, Nanjing, China; ${ }^{2}$ College \\ of Pharmacy, Jiangsu University, \\ Zhenjiang, China; ${ }^{3}$ Department of \\ Chemical Engineering, Northeastern \\ University, Boston, MA, USA; ${ }^{4}$ School \\ of Engineering, China Pharmaceutical \\ University, Nanjing, China \\ *These authors contributed equally \\ to this work
}

Correspondence: Jiasheng Tu Department of Pharmaceutics, Center for Research Development and Evaluation of Pharmaceutical Excipients and Generic Drugs, School of Pharmacy, China Pharmaceutical University, 24 Tongjiaxiang Road, Gulou District, Nanjing, Jiangsu, 210009, China

Tel +86258327 I305

Email jiashengtu@aliyun.com

Runing Sun

School of Engineering, China

Pharmaceutical University,

24 Tongjiaxiang Road, Gulou District,

Nanjing, Jiangsu, 210009, China

Tel +862586I8574I

Email herbal_sun@163.com
Introduction: Cyclosporine-A (CsA) is generally used as an immunosuppressant and is also prescribed for some ophthalmic applications such as vernal keratoconjunctivitis and dry eye. However, it is limited clinically due to its low aqueous solubility and ocular bioavailability.

Methods: In this work, lyophilized methoxy poly(ethylene glycol)-poly(lactide) (mPEG-PLA) polymer micelles were prepared for ophthalmic formulations as a promising nano-carrier for hydrophobic drugs like CsA. A mPEG-PLA diblock polymer was synthesized by ring opening polymerization and CsA was loaded into mPEG-PLA micelles by a simple film dispersion method. A uniform design of experiments was utilized to optimize the final formulation. The obtained formulation was characterized for diameter $(57.0 \pm 3.2 \mathrm{~nm})$, entrapment efficiency $\%(98.51 \pm 1.4)$, and in vitro release. Moreover, incorporating the stabilizer mPEG2000 could increase the in vitro stability of the lyophilized CsA-loaded mPEG-PLA micelles.

Results: Results showed a sustained release of CsA from the micelles. Drug concentration and time-dependent cytotoxicity of human corneal epithelial-2 cells was observed. Additionally, the transcorneal mechanism of mPEG-PLA micelles was studied and the results showed that the mPEG-PLA micelles mainly absorbed by a paracellular pathway via corneal epithelial cells.

Conclusion: Taken together, the results proved that this mPEG-PLA diblock polymer can be potentially used as a nanoscopic carrier to deliver hydrophobic drugs in a controlled manner to the ocular region and, thus, deserves further attention.

Keywords: CsA, mPEG-PLA micelles, lyophilization, physicochemical characteristics, transcorneal mechanism

\section{Introduction}

Cyclosporine-A (CsA; Figure 1) is a cyclic peptide compound composed of 11 amino acids, which is most commonly used in the clinic. ${ }^{1} \mathrm{CsA}$ is also known as a calcineurin inhibitor which can form a complex with cyclophilin-A and, as a result, inhibit T-cell activation by preventing translocation of the nuclear factor of activated T-cells to the nucleus. Furthermore, it blocks the expression of interleukin (IL)-2, IL-3, IL-4, tumor necrosis factor-2, and other cytokines. ${ }^{2}$ In addition, it can inhibit apoptosis by binding to cyclophilin-D. ${ }^{3}$ Due to its high lipophilicity $(\log \mathrm{P}=3.0)$ and extremely low aqueous solubility $(6.6 \mu \mathrm{g} / \mathrm{mL})$, it is difficult to formulate for conventional topical ocular delivery systems. ${ }^{4}$ Attempts have been made to improve the aqueous solubility of CsA using penetration enhancers or surfactants, such as benzalkonium chloride and macrogolglycerol ricinoleate (Kolliphor ${ }^{\circledR}$ EL; BASF, Ludwigshafen, Germany), with the former also commonly used as a preservative in ocular formulations. ${ }^{5}$ Although all of these excipients can improve the solubility and penetration of CsA, their use is limited 

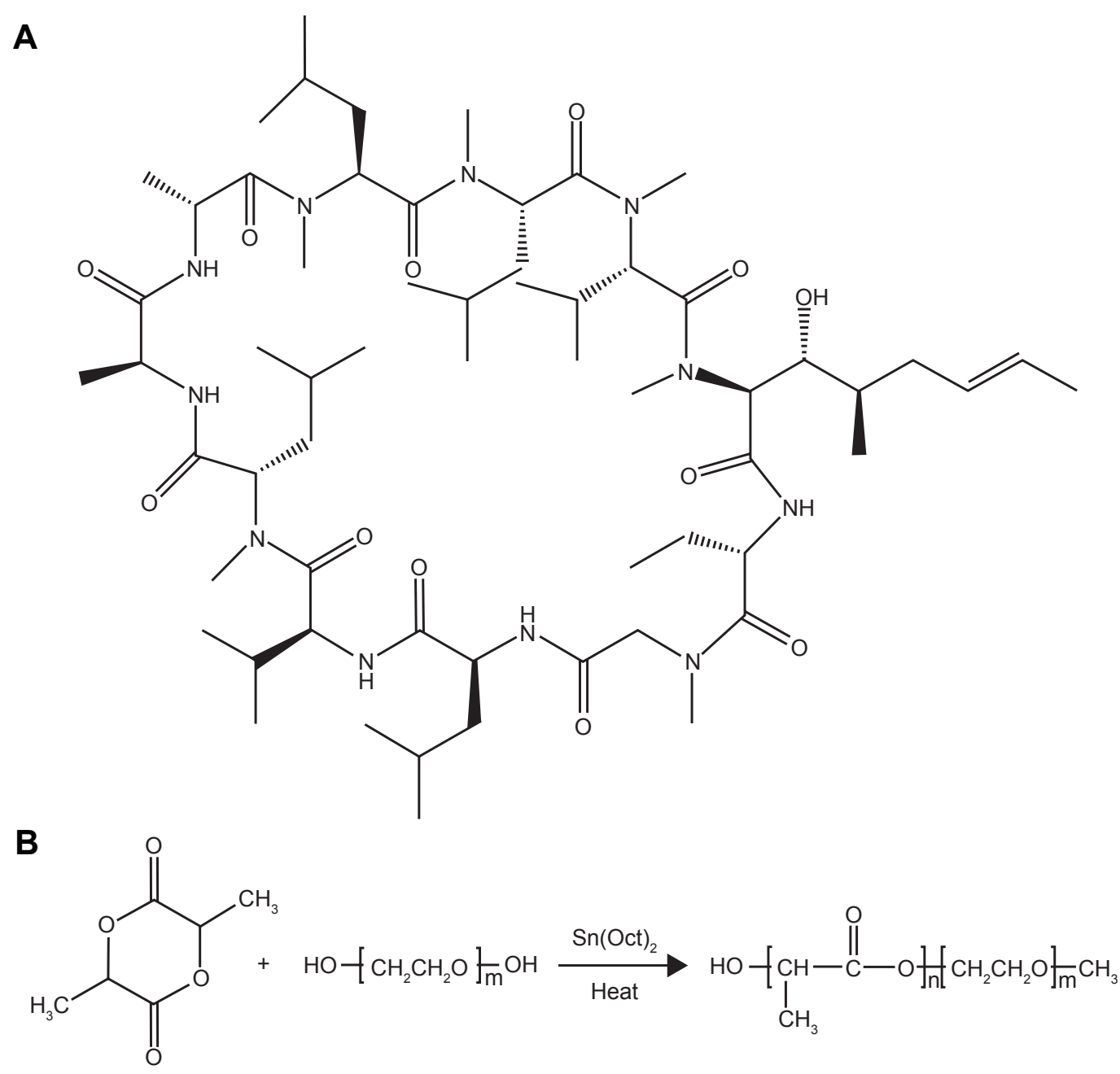

Figure I (A) Chemical structure of CsA. (B) Synthesis of block copolymer mPEG-PLA.

Abbreviations: CsA, cyclosporine-A; mPEG, methoxy poly(ethylene glycol); PLA, poly(lactide).

by their high ocular irritation. This irritation is mainly caused by compromising the integrity of the ocular tissues..$^{6-8}$

Commercial products of CsA available in the market are $0.05 \%$ CsA emulsion (Restasis ${ }^{\circledR}$, Allergan) and Ikervis ${ }^{\circledR}$ (Santen). Restasis ${ }^{\circledR}$, marked in 2003 in the USA, is an anionic emulsion of castor oil in water. It contains $0.5 \mathrm{mg} / \mathrm{mL}$ CsA and is applied twice a day. Ikervis ${ }^{\circledR}$ was marked in 2015 in Europe and is a nanoemulsion containing $1 \mathrm{mg} / \mathrm{mL}$ CsA. It is the only approved "once a day" formulation, thanks to the presence of cetalkonium chloride, which imparts a positive charge to the nanodroplets, thus prolonging the contact time with the epithelial layers of the eye by electrostatic interactions between the positively charged droplets and negatively charged mucus protein of the corneal epithelium. ${ }^{9}$ Due to the net positive charge of the oil nanodroplets, the residence time and the ocular bioavailability of CsA are higher with the cationic emulsion than with other formulations. ${ }^{10}$ However, they are always accompanied with adverse reactions such as visual disturbance, ocular burning, ocular hyperemia, eyelid erythema, etc. ${ }^{11,12}$

Many approaches have been explored for improving biomolecule solubility and bioavailability including using permeability enhancers, ${ }^{13}$ mucoadhesive polymers, ${ }^{14}$ viscosity enhancers, ${ }^{15}$ and novel formulations such as microemulsions, ${ }^{16}$ microspheres, ${ }^{17}$ liposomes, ${ }^{18}$ and micelles. ${ }^{19}$ All of the aforementioned systems have low corneal permeability. Low corneal permeability along with limited retention time of ophthalmic formulations results in low bioavailability and conjunctival uptake. ${ }^{20-23}$ Among these, the use of polymeric micelles is an attractive strategy for improving the corneal and conjunctival penetration of drugs, for prolonged therapy with reduced systemic side effects. ${ }^{24}$ Polymer micelles (PMs) are formed from amphiphilic copolymers, which comprise a hydrophobic inner core surrounded by a hydrophilic outer shell. ${ }^{25,26} \mathrm{PMs}$ can encapsulate various drugs into their inner cores with relatively high stability and the hydrophilic corona 
can be stabilized on the core surface by covalent conjugation. ${ }^{27}$ Poly(ethylene glycol) (PEG) and poly(lactide) (PLA) are widely used for fabricating biodegradable nanoparticles because of their biocompatibility and biodegradability. ${ }^{28,29}$ Researchers have also focused on the addition of PEG to the micelles to improve the stability of the micelles in physiological environments as well as precorneal fluid. ${ }^{30}$ It has been reported that methoxy PEG (mPEG)-PLA polymeric micelles, which are used as carriers of hydrophobic compounds, can increase drug solubility and penetration..$^{25}$

The stability of PMs plays important roles during storage, handling, and clinical use. One approach to keep the micelles stable is complete removal of water by lyophilization. However, many PM formulations are unstable in lyophilized form also, but the incorporation of some excipients (such as polysaccharides and amino acids) can solve this problem. These excipients can prevent nanoparticle fusion by interparticle bridging during freeze drying processes. ${ }^{31}$ Herein, we describe a lyophilized CsA-loaded mPEG-PLA micelle with the stabilizer mPEG2000 to improve its in vitro stability.

\section{Materials and methods Materials}

CsA was purchased from Nanjing Duly Biotechnology Co., Ltd (Nanjing, China). mPEG (molecular weight [MW] 2,000) stannous octate was obtained from Sigma-Aldrich Co. (St Louis, MO, USA). D,L-lactide (purity: 99.5\%) was purchased from Jinan Daigang Biomaterial Co, Ltd (Jinan, China). Hydroxypropyl methylcellulose (HPMC) (Methocel E4M) was obtained from Colorcon (Shanghai, China). EDTA2Na was purchased from Guangzhou Lexin Huagong Co, Ltd (Guangzhou, China). MTT was provided by Sunshine Biotechnology Co, Ltd (Nanjing, China). Methanol (HPLC grade, $99.9 \%$ ) was supplied by Tedia Chemical (Fairfield, OH, USA). Distilled water was made from an OPH-II-10T Ultra Pure Water System (Sichuan Top Ultra Pure Technology Co., Ltd., Sichuan, China). All other reagents used were of analytical grade obtained from various commercial sources.

Human corneal epithelial (HCE-2) cells purchased from the American Type Culture Collection $\left(\mathrm{ATCC}^{\circledR}\right.$ number CRL-11135; Manassas, VA, USA) were cultured in $75 \mathrm{~cm}^{2}$ flasks in DMEM/F12 (Thermo Fisher Scientific, Waltham, MA, USA) containing $10 \%$ fetal calf serum, $100 \mathrm{U} / \mathrm{mL}$ penicillin $\mathrm{G}$, and $100 \mu \mathrm{g} / \mathrm{mL}$ streptomycin sulfate in a $37^{\circ} \mathrm{C}$, $5 \% \mathrm{CO}_{2}$ environment.

New Zealand White rabbits weighing 2-2.5 kg were obtained from Qinglongshan Farms (Nanjing, China). All rabbits were healthy and free of clinically observable ocular surface disease. All animal experiments complied with the requirements of the National Institute of Health Guide for Care and procedures were approved by the China Pharmaceutical University Animal Experiment Center.

\section{Synthesis and characterization of the mPEG-PLA diblock polymer}

mPEG-PLA diblock polymers with different weight ratios (40:60, 50:50, 60:40) were synthesized by ring opening polymerization as described previously. ${ }^{32}$ Briefly, D,L-lactide and mPEG2000 at a certain ratio were added into a three necked round bottle flask with a magnetic stirrer. Under nitrogen flushing, the materials were heated up to $140^{\circ} \mathrm{C}$ slowly until they completely melted; then $0.5 \%$ stannous octate (w/v) was added as a solution in toluene. The above mixed solution was allowed to incubate in the presence of nitrogen for 6 hours at $160^{\circ} \mathrm{C}$. The cooled product was dissolved in dichloromethane, recovered by precipitation into excess solvent of ethyl ether, and then the process was repeated twice. The purified copolymers were dried in a vacuum oven at $40^{\circ} \mathrm{C}$ for 24 hours and stored in a desiccator for further use.

The composition and the average MW of each copolymer were determined using $300 \mathrm{MHz}{ }^{1} \mathrm{H}$-nuclear magnetic resonance ( ${ }^{1} \mathrm{H}-\mathrm{NMR}$; Bruker AV-500; Bruker Optik GmbH, Ettlingen, Germany) in D-chloroform and differential scanning calorimetry (DSC; TA Instruments, New Castle, DE, USA). The integrals of the peaks corresponding to the mPEG methene protons ( $3.5 \mathrm{ppm}$ ), the PLA methyl protons (1.5 ppm), and methine protons (5.1 ppm) were applied to determine the weight ratio of $\mathrm{MPEG}$ to PLA and to calculate the average MW. The thermal properties of the copolymers were studied by DSC.

\section{Preparation of CsA-loaded micelle ophthalmic preparations}

In order to form CsA-loaded micelles, CsA and mPEGPLA at different weight ratios (40:60, MW: 5,000; 50:50, MW: 4,000; 60:40, MW: 3,333) were dissolved in $1 \mathrm{~mL}$ of acetonitrile. After that, the organic content from the mixture was completely removed using a vacuum rotary evaporator at $50^{\circ} \mathrm{C}$. The dried film of the micelle was dispersed in saline and filtered through a membrane filter followed by centrifugation at $8,000 \mathrm{rpm}$ to remove free CsA. Further, CsA-loaded micelle ophthalmic preparations were obtained by suspension and by the addition of a saline solution containing thickener HPMC and the osmolality of the suspension was adjusted with EDTA-2Na. The final preparation was a filtrate and 
vortexed for 5 minutes to get a uniform mixer. Afterward, the volume of the obtained solution was adjusted to an initial volume with normal saline and the solution was filtered with a 0.22- $\mu \mathrm{m}$ cellulose nitrate membrane (Agilent Technologies, Santa Clara, CA, USA) for sterilization. Finally, the supernatant was collected for further analysis.

\section{The critical micelle concentration (CMC) of mPEG-PLA micelles}

The CMC of mPEG-PLA micelles with different weight ratios was determined by using pyrene as a fluorescence probe. ${ }^{33}$ About $200 \mu \mathrm{L}$ of $5 \mu \mathrm{g} / \mathrm{mL}$ pyrene solution in acetone was added in 14 of the $10-\mathrm{mL}$ flasks and acetone was dried by $\mathrm{N}_{2}$. Different concentration mPEG-PLA solutions were added into the flasks with the pyrene. The concentration of mPEG-PLA solutions ranged from 0.1 to $2,000.0 \mu \mathrm{g} / \mathrm{mL}$. The flasks were kept in a shaker at $25^{\circ} \mathrm{C}$ for 24 hours and light was avoided to reach equilibrium before fluorescence measurements.

Fluorescence spectra were recorded by a fluorescence spectrometer (Lumina; Thermo Fisher Scientific). The emission wavelength was fixed at $390 \mathrm{~nm}$ and the excitation and emission bandwidths were $5 \mathrm{~nm}$. The CMCs of mPEG-PLA micelles were the crossover points in the plots of the fluorescence intensity ratio of $338 \mathrm{~nm}\left(\mathrm{I}_{338}\right)$ and $333 \mathrm{~nm}\left(\mathrm{I}_{333}\right)$ to the logarithm concentration.

\section{Optimization of the preparation process}

In order to optimize the micellar preparation process, single factor experiments and a uniform design were applied. In single factor experiments, the CsA residue in the rabbit tear after the administration of 2 minutes was considered an indicator to choose the block ratio of $\mathrm{mPEG}$ to PLA. Based on the results of single factor experiments, a uniform design was applied to determine the optimum amount of the excipients in ophthalmic preparations. According to the experimental design, the accurate requirement, independent variables $\mathrm{X}_{1}$ (the ratio of the drug to polymer), $\mathrm{X}_{2}$ (HPMC), and $\mathrm{X}_{3}$ (EDTA-2Na), was designed at five variable levels in the optimization process and is listed in Table 1.

Table I The uniform design factors and levels

\begin{tabular}{l|l|l|l|l|l}
\hline \multirow{2}{*}{$\begin{array}{l}\text { Independent } \\
\text { variables }\end{array}$} & \multicolumn{4}{|l}{ Levels } \\
\cline { 2 - 6 } & $\mathbf{I}$ & $\mathbf{2}$ & $\mathbf{3}$ & $\mathbf{4}$ & $\mathbf{5}$ \\
\hline $\mathrm{X}_{1}$ : Drug:polymer (\%) & 0.37 & 0.74 & 1.10 & 1.45 & 1.84 \\
$\mathrm{X}_{2}:$ HPMC (\%) & 0 & 0.5 & 1.0 & 1.5 & 2.0 \\
$\mathrm{X}_{3}$ : EDTA-2Na (\%) & 0.01 & 0.02 & 0.03 & 0.04 & 0.05 \\
\hline
\end{tabular}

Abbreviation: HPMC, hydroxypropyl methylcellulose.

\section{CsA determination in rabbit tears}

To determine the presence of $\mathrm{CsA}$ in rabbit tears, a single dose of $60 \mu \mathrm{L}$ CsA formulation $(0.5 \mathrm{mg} / \mathrm{mL})$ was administered in the eyes of New Zealand White rabbits. All the experiments were performed under the Protocol of Ethical Committee Permission of China Pharmaceutical University. Tear fluid samples were collected by using Schirmer test strips. ${ }^{34}$ Briefly, the amount of tears withdrawn was calculated by subtracting the weight of each strip after sampling from the weight before sampling. The eyelids were gently held to close during sampling in order to prevent loss of the eye drops. Subsequently, the Schirmer strips were placed in an Eppendorf tube, dried under $\mathrm{N}_{2}$ stream, and then $0.2 \mathrm{~mL}$ of the mobile phase was added. The sample was vortexed for 30 seconds to dissolve CsA into the mobile phase and centrifuged at 10,000 rpm for 5 minutes (KDC-140HR; Anhui USTC Zonkia Scientific Instruments Co, Ltd, Anhui, China). The concentration of CsA in the supernatant was determined by HPLC (Thermo Fisher Scientific) and the presence of CsA was ascertained.

The concentration of CsA was calculated by HPLC. HPLC analysis was performed on a reverse C18 column (4.6×250 mm, 5 Hm, ZORBAX Eclipse Plus C18; Agilent Technologies). The mobile phase consisted of a mixture of methanol, water, and phosphoric acid at a ratio of 85:15:0.05 $(\mathrm{v} / \mathrm{v} / \mathrm{v})$, respectively. The detector wavelength, flow rate, injection volume, and column temperature were adjusted at $225 \mathrm{~nm}, 1 \mathrm{~mL} / \mathrm{min}, 20 \mu \mathrm{L}$, and $70^{\circ} \mathrm{C}$, respectively. The HPLC method was validated with respect to linearity, repeatability, limit of quantitation, and limit of detection.

\section{Characterization of CsA-loaded mPEG- PLA micelles}

\section{Size distribution and zeta potential}

Mean particle size and size distribution of the micelles were measured by a ZetaPlus laser particle size analyzer (Brookhaven Instruments Corporation, Holtsville, NY, USA). The micelles were diluted in saline $\left(25^{\circ} \mathrm{C}\right)$ before the measurement. All measurements were performed in triplicate. The zeta potential of the micelles was detected in the same instrument at $25^{\circ} \mathrm{C}$.

\section{Transmission electron microscopy (TEM)}

A drop of the CsA micelle solution with a concentration of $0.5 \mathrm{mg} / \mathrm{mL}$ was attached to the copper network and was mixed with a drop of $2 \%(\mathrm{w} / \mathrm{v})$ phosphotungstic acid. The morphology of the CsA micelles was examined by a transmission electron microscope (JEM-1400; JEOL, Tokyo, Japan) using standard protocols. 


\section{Determination of entrapment efficiency (EE\%) and drug loading (DL\%)}

To determine the percentages of EE and DL of CsA in the micelles, $1 \mathrm{~mL}$ of the micellar solution was diluted with methanol to disrupt the self-assembled structures and the amount of CsA was then determined using the validated HPLC method. EE\% and DL\% was calculated by the following equations:

$$
\begin{aligned}
& \mathrm{EE} \%=\frac{\text { Weight of drug in micelles }}{\text { Weight of the fed drug }} \times 100 \% \\
& \mathrm{DL} \%=\frac{\text { Weight of drug in micelles }}{\text { Weight of the micelles }} \times 100 \% .
\end{aligned}
$$

\section{Effect on the $\mathrm{pH}$ and temperature on stability}

According to the method described in the Preparation of CsA-loaded micelle ophthalmic preparations section, all of the parameters were fixed except the $\mathrm{pH}$ of the hydrated buffer solution; the $\mathrm{pH}$ of the solution was adjusted at 4.0, 5.0, 6.0, 7.0, 8.0, and 10.0, respectively. The CsA micelle solution was incubated at different $\mathrm{pH}$ values and was sealed in colorless glass vials. To protect from light, all vials were wrapped with aluminum foil and stored at $4{ }^{\circ} \mathrm{C}, 25^{\circ} \mathrm{C}$, and $37^{\circ} \mathrm{C}$, respectively. After 24 hours, the EE\% of each CsAloaded micelle was determined.

\section{Determination of physical stability}

To evaluate physical stability, the ophthalmic preparations were sealed in transparent glass vials and stored in strong light and high temperature environments in both solution and lyophilized form. The samples were exposed to an artificial daylight fluorescent lamp with $4,500 \pm 500 \mathrm{Lx}$ for 10 days to test photostability. The temperature stability was studied at two temperature conditions at $40^{\circ} \mathrm{C}$ and $60^{\circ} \mathrm{C}$ for 10 days, respectively. At the end of the study, the samples were tested for CsA content and size of micelles. The stability of the lyophilized powder was measured in terms of CsA content and water dispersibility.

\section{Preparation and optimization of lyophilized CsA-loaded polymeric micelles}

Lyophilized CsA-loaded polymeric micelles were prepared by the optimized formulation method. To prevent leaching of the payload from micelles during freeze drying, some excipients were used as a cryoprotectant. In this case, six excipients were used as stabilizers: glucose, sucrose, L-glutamic acid, sorbitol, mannitol, and mPEG2000. The CsA-loaded micelle solution $(1 \mathrm{~mL})$ and $50 \mathrm{mg}$ of a stabilizer $(5 \%, \mathrm{w} / \mathrm{v})$ were pipetted into a 5-mL glass vial and kept in a lyophilizer (LGJ10FD; Beijing Songyuan Huaxing Technology Develop Co, Ltd, Beijing, China) for 43 hours to obtain lyophilized CsAloaded ophthalmic preparations.

\section{In vitro release study}

Initially, the calculated weight of the micelle powder was dispersed in $2 \mathrm{~mL}$ of saline at $37^{\circ} \mathrm{C}$ and $1 \mathrm{~mL}$ from it was transferred into a dialysis bag (Shanghai Yuanye BioTechnology Co, Ltd, Shanghai, China) with a $3.5-\mathrm{kDa}$ MW cutoff. After that, the resulting system was placed in a suitable container containing $10 \mathrm{~mL}$ of release media (phosphate buffer solution, $\mathrm{pH}=6.8 \%$ and $0.25 \%$ sodium lauryl sulfate [SLS]) and the container was placed in a shaker with water bath at $37^{\circ} \mathrm{C}$. The shaker was adjusted to rotate at $100 \mathrm{rpm} / \mathrm{min}$. Samples from the released media were collected and replaced in equal volumes $(1 \mathrm{~mL})$ each time as per the defined study protocol. The content of CsA in the released media at each time interval was measured by the HPLC method.

\section{In vitro cytotoxicity tests}

Cell viability was measured by the MTT assay method; HCE-2 cells were seeded in 96-well plates at an initial cell density of 8,000 cells/well. After 24 hours incubation of the cells, fresh medium containing different concentrations of free CsA $(0.1,1,10,50,100$, and $200 \mu \mathrm{g} / \mathrm{mL})$, blank, or CsA-loaded mPEG-PLA micelles $(0.1,0.5,1$ and $5 \mathrm{mg} / \mathrm{mL}$ ) was added. To determine the concentration and time-dependent cytotoxicity of the free CsA solutions, blank, and CsA-loaded mPEG-PLA micelles, the study was performed for 24 and 48 hours at $37^{\circ} \mathrm{C}$ on HCE-2 cells. After the incubation, media were removed and $200 \mu \mathrm{L}$ $(0.5 \mathrm{mg} / \mathrm{mL})$ of the MTT solution was added in each well and incubated for another 4 hours at $37^{\circ} \mathrm{C}$. Since the live cells metabolize MTT and form formazan crystals, $150 \mu \mathrm{L}$ of dimethyl sulfoxide was added to dissolve the formazan crystals. Absorbance values were measured by reading the plates at $570 \mathrm{~nm}$ on a microplate reader (ELx800; BioTek Instruments, Winooski, VT, USA), and the viability percentage was calculated. The inhibition rate was calculated according to the following formula:

$$
\text { Cell viability }=\frac{I_{\text {sample }}-I_{\text {blank }}}{I_{\text {control }}-I_{\text {blank }}} \times 100
$$




\section{In vivo eye irritation test}

The in vivo eye irritation test of mPEG-PLA micelles with different weight ratios was performed in three groups of 12 New Zealand White rabbits. CsA micelles $(25 \mu \mathrm{L}$; $0.5 \mathrm{mg} / \mathrm{mL}$ ) were instilled into the lower conjunctival sac of the rabbit's right eye and physiological saline was used as the control in the left eye by single dosing per day for 3 weeks. Then, the rabbits were euthanized and the ocular tissues were extracted; the cornea, conjunctiva, sclera, iris were collected and stored in $10 \%$ formalin solution $(\mathrm{v} / \mathrm{v})$ at $4^{\circ} \mathrm{C}$. The tissue was embedded in paraffin, serially sectioned into $5-\mu \mathrm{m}$ thick sections, and stained with H\&E. The histological slides were evaluated using a JFMV300CG camera lens and JFMV controller software (Nan Jing Ji Fei Technology Co, Ltd, Nanjing, China).

\section{Transcorneal mechanism of mPEG-PLA micelles across the ocular barrier}

In order to study the transcorneal mechanism of mPEGPLA micelles across the ocular barrier, fluorescent micelles incorporating fluorescein as a fluorescent marker were prepared. Fluorescein is insoluble in water and has a similar dissolution property to CsA. On the other hand, it is widely used as a fluorescent tracer. Consequently, fluorescein was selected as a fluorescent marker that was loaded in the micelles in the same way as CsA was loaded. A single dose $(3 \times 25 \mu \mathrm{L}$, at 10 -minute intervals) of the micelle formulations containing $15 \mu \mathrm{g} / \mathrm{mL}$ fluorescein was instilled into the lower conjunctival sac of one eye for each rabbit. Meanwhile, a transport study of fluorescein-loaded micelles was performed in the presence of EDTA to open the paracellular route by chelation with calcium at a concentration of $0.25 \% \mathrm{w} / \mathrm{v} .{ }^{35}$ The untreated contralateral eye was used as a control and $15 \mu \mathrm{g} / \mathrm{mL}$ of the fluorescein solution was instilled into the control eye. At 2 hours post-administration, rabbits were sacrificed with $\mathrm{CO}_{2}$ gas and freshly excised corneal specimens were collected. The corneas were rinsed with $0.9 \% \mathrm{w} / \mathrm{v}$ sterile $\mathrm{NaCl}$ and placed in $4 \% \mathrm{v} / \mathrm{v}$ formalin solution. Finally, the corneas were observed with a confocal laser scanning microscope (Carl Zeiss Meditec AG, Jena, Germany).

\section{Statistical analyses}

Data were analyzed using SPSS software, version 19 (IBM Corporation, Armonk, NY, USA). Statistical comparisons were performed by one-way ANOVA for different groups. Significant differences between or among groups were indicated by $* P<0.05, * * P<0.01$, and $* * * P<0.001$. All data were presented as mean $\pm \mathrm{SD}$.

\section{Results and discussion Polymer synthesis and micellization}

mPEG-PLA was synthesized by ring opening polymerization of D,L-lactide and mPEG2000 using a $0.5 \%(\mathrm{w} / \mathrm{v})$ stannous octate catalyst, as shown in Figure 1B. A series of mPEGPLA copolymers with different weight ratios were successfully synthesized and characterized as listed in Table 2 and Figure 2. The weight ratio of mPEG to PLA was calculated from ${ }^{1} \mathrm{H}-\mathrm{NMR}$ spectra. The obtained DSC spectra were not significantly different from the initial weight ratio. Melting enthalpies decreased as the content of lactide increased, due to the reduction in crystallization of mPEG in the copolymer. ${ }^{36}$

Micelles were formed by self-assembly whereby the water insoluble mPEG-PLA was dissolved in acetonitrile; then, a vacuum rotary evaporator was used to form a transparent colloid. The obtained colloid was dispersed into saline to get the colloidal suspension. The hydrophobic PLA backbone aggregated together to form the micelle core. The hydrophilic mPEG chains formed the micelles corona, thereby stabilizing the hydrophobic-hydrophilic interface by limiting the interaction between the core and the aqueous solution. ${ }^{37}$

\section{CMC of mPEG-PLA micelles}

The CMC of mPEG-PLA with different weight ratios was determined using pyrene as probe..$^{38}$ Figure 3 reports the ratio of the $I_{338}$ to the $I_{333}$ vibronic peak of pyrene as a function of surfactants concentration. Two different linear regions can be identified in each profile; since $\mathrm{I}_{338} / \mathrm{I}_{333}$ indicates the polarity of the medium in which pyrene is dissolved, the two regions correspond to pre-micelles and post-micelles formation. $\mathrm{CMC}$ can thus be estimated from the crossover concentration. ${ }^{29}$ The CMC of mPEG-PLA with a weight ratio of 60:40, 50:50, and 40:60 were 7.90, 3.05, and $1.25 \mathrm{mg} / \mathrm{L}$, respectively. The CMC value of mPEG-PLA was decreased with the increase of hydrophobic block PLA, with the reason being that PLA strengthened the hydrophobic interactions

Table 2 Characteristics of mPEG-PLA synthesized polymers

\begin{tabular}{l|l|l|l}
\hline $\begin{array}{l}\text { Weight ratio } \\
\text { (w/w) mPEG:PLA }\end{array}$ & 'H-NMR & \multicolumn{2}{|l}{ DSC } \\
\cline { 2 - 4 } & $\begin{array}{l}\text { Weight ratio } \\
\text { of mPEG to } \\
\text { PLA }^{\text {b }}\end{array}$ & $\begin{array}{l}\text { Weight ratio } \\
\text { of mPEG to } \\
\text { PLA }^{c}\end{array}$ & $\begin{array}{l}\text { Melting } \\
\text { point } \\
\left({ }^{\circ} \mathbf{C}\right)\end{array}$ \\
\hline $60: 40$ & $64: 34$ & $61: 39$ & 48.8 \\
$50: 50$ & $45: 55$ & $48: 52$ & 43.6 \\
$40: 60$ & $37: 63$ & $38: 62$ & 41.0 \\
\hline
\end{tabular}

Notes: aWeight ratio of mPEG to PLA was the actual weight ratio. 'Weight ratio of $\mathrm{mPEG}$ to PLA was the weight ratio of $\mathrm{mPEG}$ to PLA calculated from 'H-NMR spectra. 'Weight ratio of $\mathrm{mPEG}$ to PLA was the weight ratio of $\mathrm{mPEG}$ to PLA in the copolymers, calculated from DSC.

Abbreviations:DSC, differentialscanning calorimetry;mPEG, methoxy poly(ethylene glycol); NMR, nuclear magnetic resonance; PLA, poly(lactide). 
A

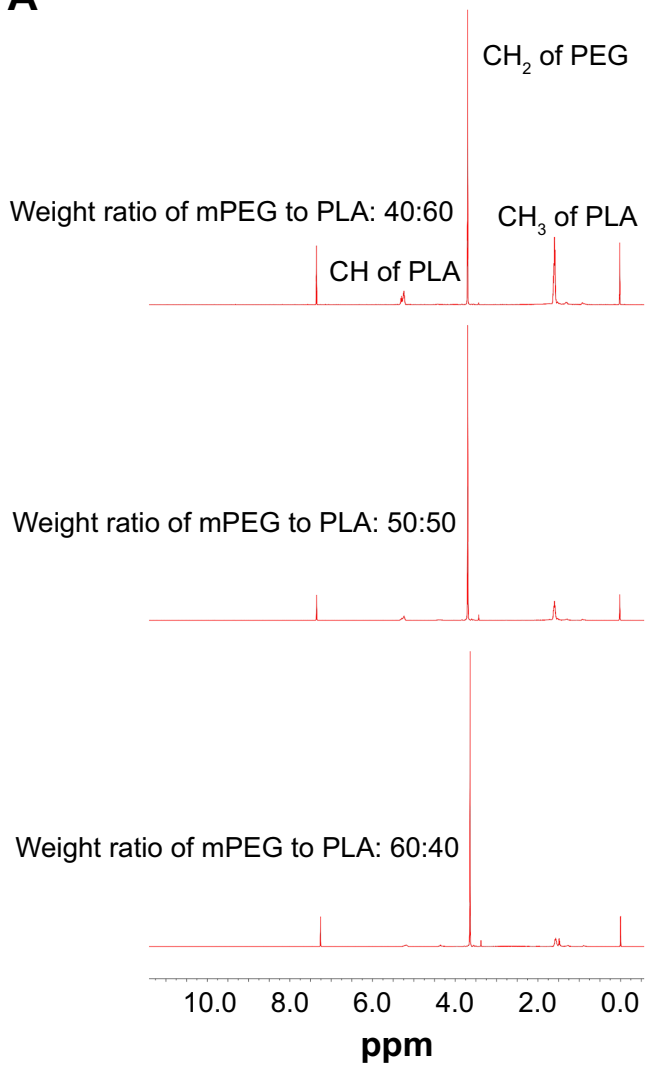

B
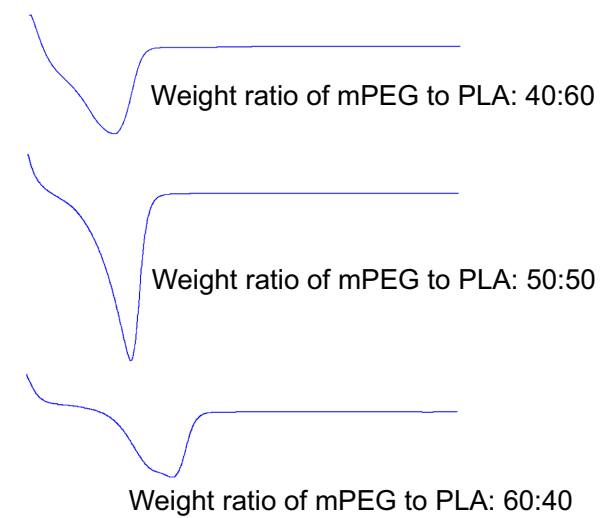

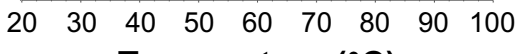

Temperature $\left({ }^{\circ} \mathrm{C}\right)$

Figure 2 (A) H-NMR spectra and (B) DSC spectra of mPEG-PLA with a weight ratio of 60:40, 50:50, and 40:60, respectively.

Abbreviations: DSC, differential scanning calorimetry; mPEG, methoxy poly(ethylene glycol); NMR, nuclear magnetic resonance; PLA, poly(lactide).

A

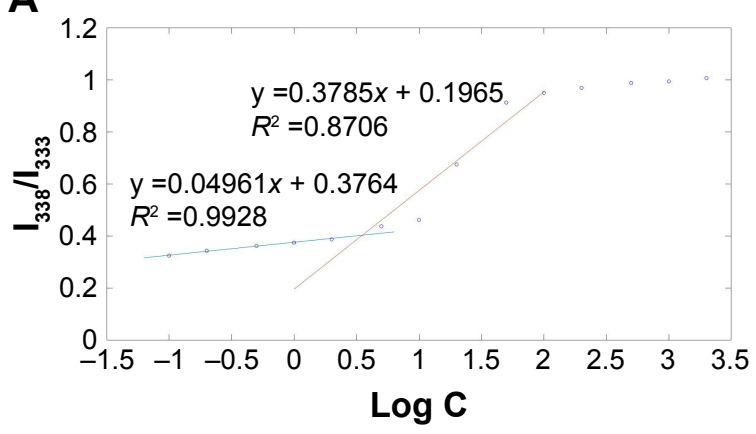

B

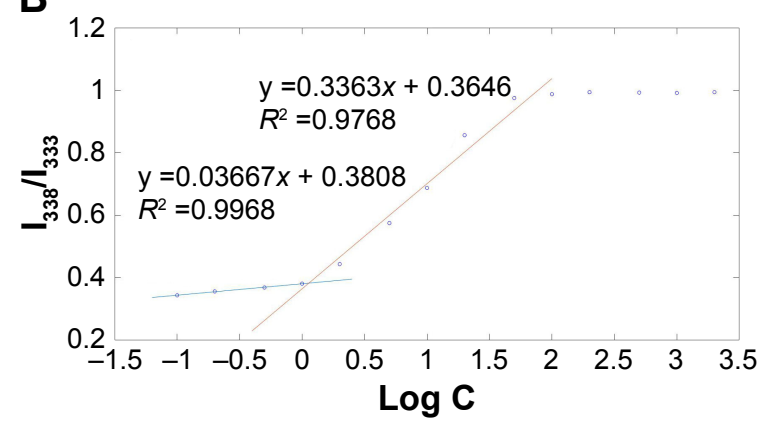

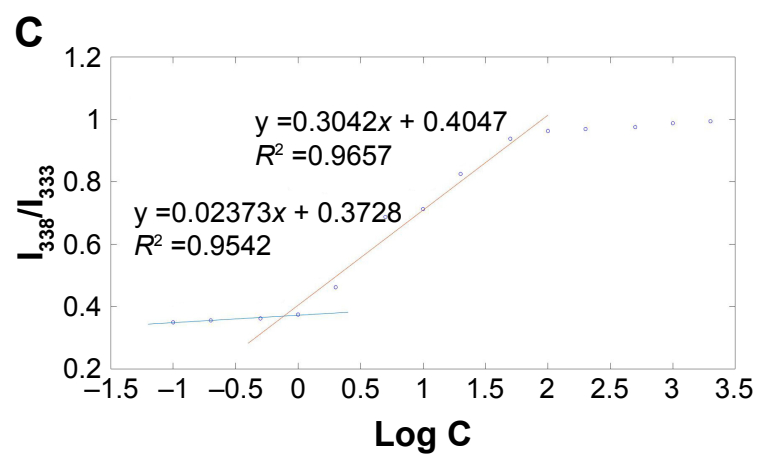

Figure 3 Plot of the fluorescence intensity ratio of $\mathrm{I}_{338} / \mathrm{I}_{333}$ from excitation spectra as a function of mPEG-PLA with a weight ratio of $(\mathbf{A}) 60: 40$ concentration, (B) $50: 50$ concentration, and (C) 40:60 concentration.

Abbreviations: mPEG, methoxy poly(ethylene glycol); PLA, poly(lactide) 
Table 3 The effect of polymer block ratio on micelles $(n=3$, mean \pm SD)

\begin{tabular}{l|l}
\hline $\begin{array}{l}\text { Block ratio (w/w) } \\
(m P E G: P L A)\end{array}$ & CsA tear concentration $(\mu \mathrm{g} / \mathrm{mL})$ \\
\hline $60: 40$ & - \\
$50: 50$ & $28.27 \pm 0.21$ \\
$40: 60$ & $25.13 \pm 0.26 *$ \\
\hline
\end{tabular}

Notes: $* P<0.05$; compared with 50:50. The "-" represents below the minimum detection of this method.

Abbreviations: CsA, cyclosporine-A; mPEG, methoxy poly(ethylene glycol); PLA, poly(lactide).

among the polymer chains at the micelle's core. The lower $\mathrm{CMC}$ value provided good stability for the drugs and remarkable resistance to dissociation and dilution due to a large volume of tear in the eye.

\section{Optimization of the preparation process}

\section{The polymer block ratio of $\mathrm{mPEG}$ to PLA}

The objective of this study was to develop a CsA ophthalmic micelle formulation to increase corneal retention. The CsA concentration in tears was determined by HPLC. As shown in Table 3, the formulation of CsA micelles could confer higher retention to CsA $(P<0.05)$, when the block weight ratio of mPEG to PLA was 50:50. Moreover, CsA could not be detected by HPLC, when the CsA micelles had a block weight ratio of mPEG to PLA equaling 60:40. Therefore, the weight ratio of 50:50 was chosen to prepare the micellar system.

\section{Formulation screening by uniform design}

As a novel drug carrier that is intended to be used in the ocular drug delivery system, one of the most important parameters was the retention $(\mathrm{Y})$ of $\mathrm{CsA}$ in the tear upon instillation. The uniform design was used to speculate optimal prescription with high CsA retention. The independent variables of the experimental runs and their responses are given in Table 4.

A regression analysis was carried out to fit the mathematical model to the experimental data aiming at an optimal region for the study. The regression equation was expressed as follows:

$\mathrm{Y}=0.548-1.2692 \mathrm{X}_{1}+2.946 \mathrm{X}_{2}-0.1228 \mathrm{X}_{3}\left(R^{2}=0.9856\right)$

The positive value of the regression coefficient indicates an effect that favors optimization, while a negative value represents an inverse relationship between the factor and the response. It can be seen that the variable with the largest and positive effect was $\mathrm{X}_{2}$ (HPMC), the negative influence of $\mathrm{X}_{1}$ (the ratio of drug to polymer), and $\mathrm{X}_{3}$ (EDTA-2Na). Based on the above results, an optimum condition for the synthesis of CsA-loaded micelles was found as follows: the amount of HPMC with a maximum level of $2 \%$, the ratio of drug to polymer $=0.37 \%$, and the amount of EDTA- $2 \mathrm{Na}=0.01 \%$.

\section{Characterization of the optimal CsA- loaded micelle ophthalmic preparations}

The CsA micelles were a transparent, slightly blue opalescent solution, and slightly off-white when compared to water (Figure 4A). The TEM image showed that the micelles were spherical or quasi-circular and homogenous, and no aggregates were present. TEM also confirmed that the micelles were spherical core-shell structures. The hydrophobic segments forming PMs could not be stained by phosphotungstic acid. As a result, these parts showed up as bright white cores under the electron microscope. The hydrophilic mPEG shells absorbed some of the phosphotungstic acid in the aqueous phase which displayed as gray halos. The core-shell structures of the micelles could control drug release and enhance drug stability ${ }^{39}$ According to particle size measurements (Figure 4B), it can be seen that the particle size of CsA-loaded mPEG-PLA micelles was about $57 \mathrm{~nm}$. The smaller size observed in the TEM image compared to that in dynamic light scattering was probably due to the drying effect during the preparation of the sample for TEM measurements. ${ }^{40}$ Furthermore, the zeta potential of CsA-loaded mPEG-PLA micelles

Table 4 The uniform design and resulting values

\begin{tabular}{l|l|l|l|l}
\hline \multirow{2}{*}{ Experiments } & \multicolumn{2}{|l|}{ Variables } & Responses \\
\cline { 2 - 5 } & $\begin{array}{l}\mathbf{X}_{\mathbf{1}}: \text { ratio of drug to } \\
\text { polymer (w/w \%) }\end{array}$ & $\mathbf{X}_{2}:$ HPMC (\%) & $\mathbf{X}_{3}:$ EDTA-2Na (\%) & Y: retention ( $\mu \mathrm{g} / \mathbf{m L})$ \\
\hline 1 & 0.37 & 0.50 & 0.04 & 21.40 \\
2 & 0.74 & 1.50 & 0.03 & 28.68 \\
3 & 1.10 & 0.00 & 0.02 & 15.08 \\
4 & 1.45 & 1.00 & 0.01 & 20.50 \\
5 & 1.84 & 2.00 & 0.05 & 26.42 \\
\hline
\end{tabular}

Abbreviation: HPMC, hydroxypropyl methylcellulose. 
was about $-1.23 \mathrm{mV}$ (Figure $4 \mathrm{C}$ ) at room temperature. The $\mathrm{EE} \%$ of the CsA micelles formulation was $98.51 \% \pm 1.4 \%$.

\section{Stability study - effects of $\mathrm{pH}$ and temperature}

Stability is a critical factor that must be considered during formulation design and development. The $\mathrm{EE} \%$ of micelles with different $\mathrm{pH}$ and temperature is presented in Figure 4D. After 1 day of storage at $4{ }^{\circ} \mathrm{C}$ and $25^{\circ} \mathrm{C}$, the results showed that there were no obvious changes in the $\mathrm{EE} \%$ of the micellar solution at different $\mathrm{pH}$ values. It was interesting to note that the CsA micelles solution at $\mathrm{pH} 10.0$ showed some white insoluble aggregates, while others did not show noticeable changes in appearance. This behavior was reasonable due to

\section{A}
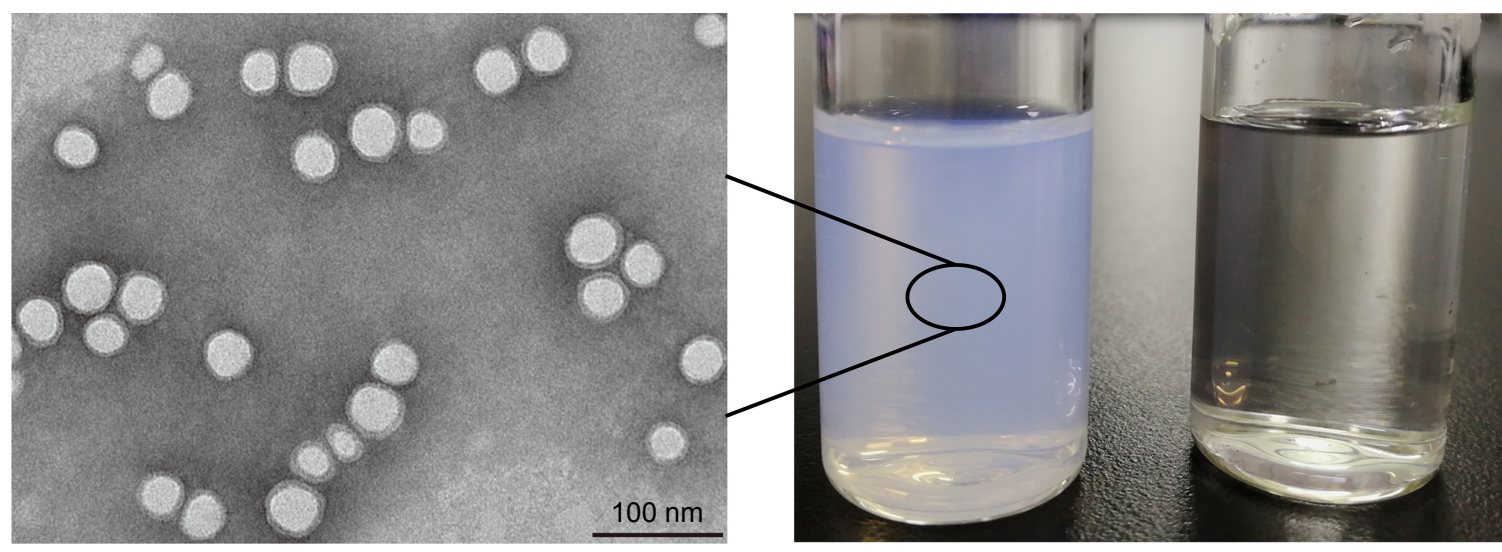

mPEG-PLA $25 \mathrm{mg} / \mathrm{mL}+$ CsA $0.5 \mathrm{mg} / \mathrm{mL}$

Water

B

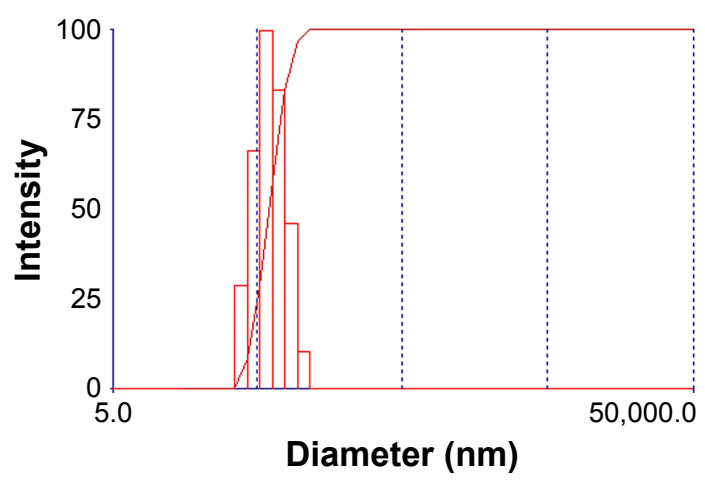

D

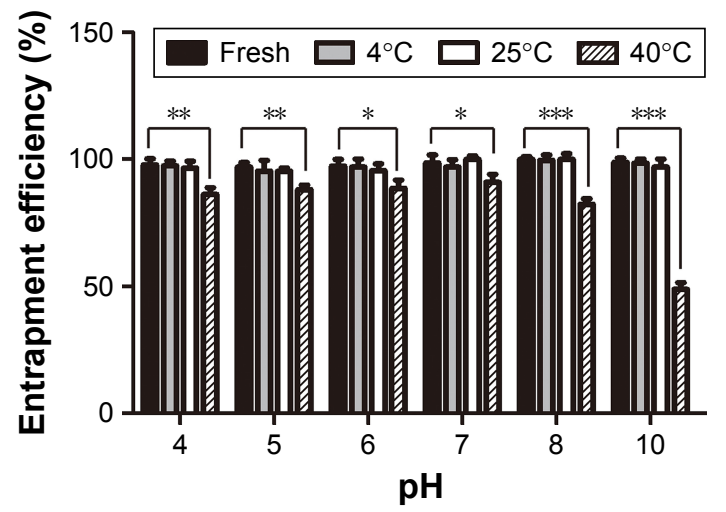

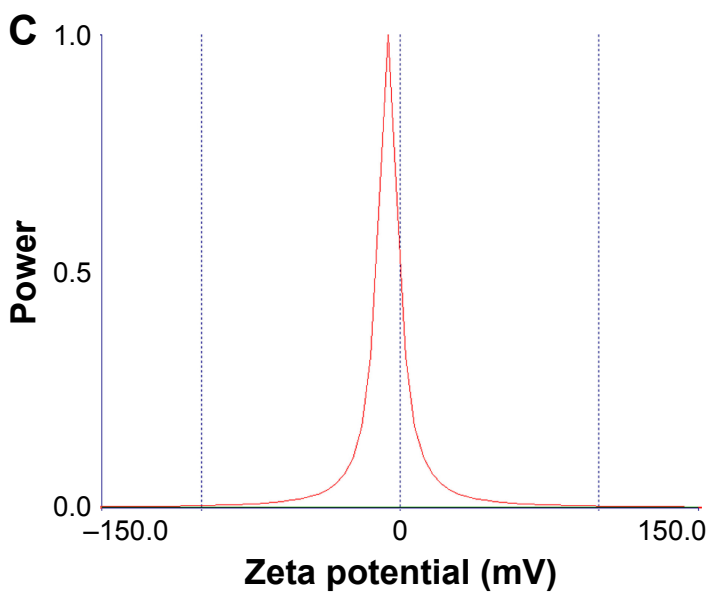

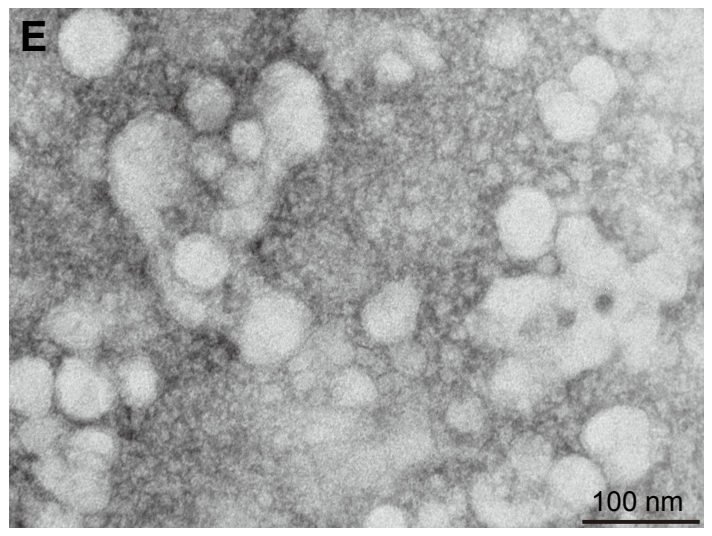

Figure 4 (Continued) 

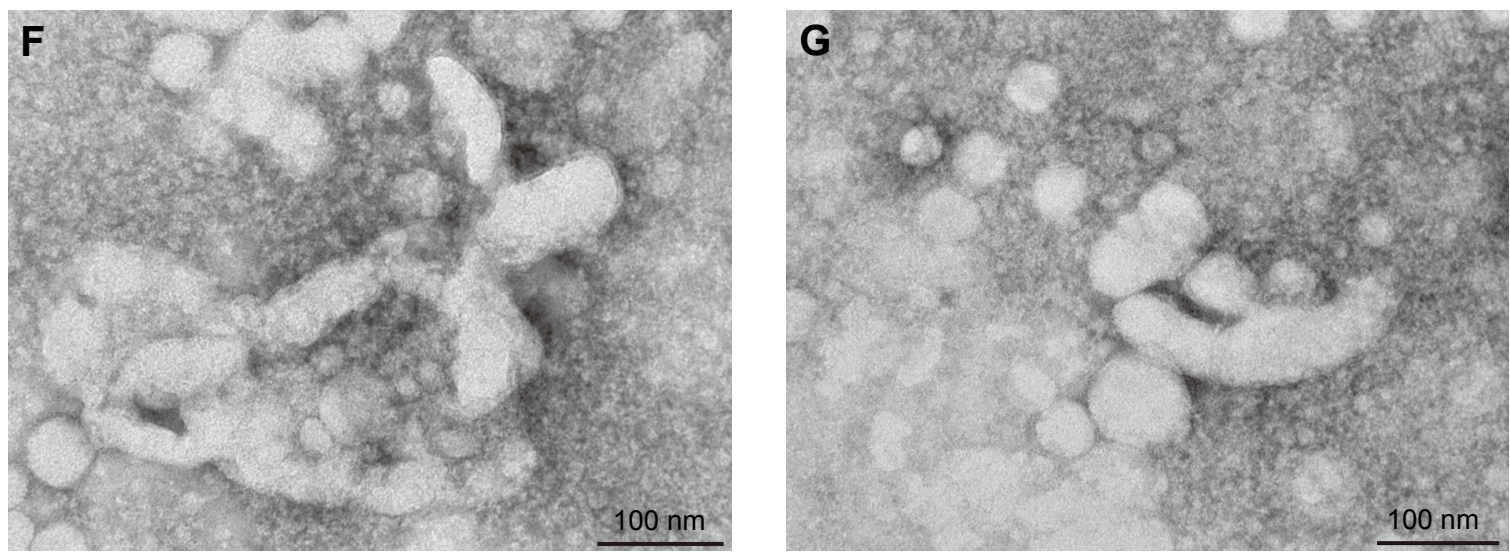

Figure 4 (A) TEM of CsA-loaded mPEG-PLA micelles and the appearance of the ophthalmic solution. (B) Representative size distribution of CsA-loaded mPEG-PLA micelles and $(\mathbf{C})$ its zeta potential analysis. (D) The stability of micelles with different $\mathrm{pH}$ and temperature. TEM of CsA-loaded mPEG-PLA micelles after 10 days stored at (E) $40^{\circ} \mathrm{C}$, (F) $60^{\circ} \mathrm{C}$, and (G) 4,500 $\pm 500 \mathrm{Lx}$ light, respectively. $\mathrm{n}=3$, mean $\pm \mathrm{SD}$. *, **, and *** represent $P<0.05, P<0.0 \mathrm{I}$, and $P<0.00 \mathrm{I}$, respectively.

Abbreviations: CsA, cyclosporine-A; mPEG, methoxy poly(ethylene glycol); PLA, poly(lactide); TEM, transmission electron micrograph.

the degradation of the mPEG-PLA copolymer under alkaline conditions. CsA was stable under alkaline and neutral conditions, while it was unstable and prone to degradation under acidic conditions. ${ }^{41}$ Our exploratory tests showed that the drug in acidic conditions showed no aggregation. It indicates that CsA was solubilized in the micelle core structure after the micelle solution was prepared, reducing the influence of the solvent, and thereby improving the stability of the drug in water.

After storing at $40^{\circ} \mathrm{C}$ for 1 day, the micelle solution with different $\mathrm{pH}$ values showed obvious turbidity and a decrease in $\mathrm{EE} \%$, and the turbidity increased with an increase in $\mathrm{pH}$. This is because CsA was degraded under acidic conditions. Under alkaline $(\mathrm{pH} \geq 8)$ and high temperature $\left(40^{\circ} \mathrm{C}\right)$ conditions, the degradation of the copolymer and the leakage of the drug led to a remarkable reduction in EE\%. ${ }^{42,43}$ These results indicated that the CsA micelles were stable at lower temperatures and at neutral conditions.

\section{Physical stability of CsA micelles in solution}

The variations of the CsA micelle solution in strong light and high temperature environment are shown in Table 5, which revealed that the stability of the CsA micelle solution was greatly influenced by light and temperature. The particle size and $\mathrm{EE} \%$ of micelles at day 0 showed significant differences compared to the micelles on other days $(P<0.05)$. Meanwhile, there were white precipitates which emerged in the vial turning the transparent solution into a turbid one. On the other hand, TEM micrographs (Figure 4E-G) indicated that the CsA micelles had changed in shape and particle size with aggregations after 10 days of storage at $40^{\circ} \mathrm{C}, 60^{\circ} \mathrm{C}$, and at 4,500 $\pm 500 \mathrm{Lx}$ light, respectively. This can explain the degradation of the mPEG-PLA block copolymer which leads to the precipitation of CsA.

\section{Formulation and optimization of the lyophilized CsA micelle ophthalmic preparations}

The lyophilized CsA-loaded polymeric micelle ophthalmic preparations were investigated due to the instability of its liquid solution. Glucose (5\%), sucrose, L-glutamic acid, sorbitol, mannitol, or mPEG2000 was chosen as a stabilizer for lyophilization of CsA polymeric micelles. The physicochemical characteristics of lyophilized CsA polymeric micelles are presented in Figure 5. The addition of mPEG2000 did not significantly affect the particle size of CsA micelles as compared with the freshly prepared CsA micelles solution $(P>0.05)$, but the addition of other stabilizers had a significant impact on the particle size of the CsA micelles $(P<0.001)$. The size distribution of CsA

Table 5 Variations of the CsA micelle solution $(n=3$, mean \pm SD)

\begin{tabular}{l|l|l|l}
\hline $\begin{array}{l}\text { Time } \\
\text { (days) }\end{array}$ & \multirow{2}{*}{$\begin{array}{l}\text { Environmental } \\
\text { conditions }\end{array}$} & \multicolumn{2}{|l}{ Characteristics } \\
\cline { 3 - 4 } & & $\begin{array}{l}\text { Particle } \\
\text { size (nm) }\end{array}$ & $\begin{array}{l}\text { Entrapment } \\
\text { efficiency (\%) }\end{array}$ \\
\hline 0 & $25^{\circ} \mathrm{C}$ & $57.00 \pm 0.65$ & $98.51 \pm 1.40$ \\
5 & $40^{\circ} \mathrm{C}$ & $61.60 \pm 11.3$ & $81.17 \pm 1.20^{* *}$ \\
5 & $60^{\circ} \mathrm{C}$ & $94.30 \pm 5.02^{* *}$ & $65.10 \pm 1.01^{* *}$ \\
5 & Light & $84.97 \pm 18.4^{*}$ & $63.03 \pm 1.01 * *$ \\
10 & $40^{\circ} \mathrm{C}$ & $90.97 \pm 3.76^{* *}$ & $74.73 \pm 0.45^{* *}$ \\
10 & $60^{\circ} \mathrm{C}$ & $131.4 \pm 12.2^{* * *}$ & $60.17 \pm 1.21^{* *}$ \\
10 & Light & $281.3 \pm 46.5^{* * *}$ & $58.47 \pm 0.78^{* *}$ \\
\hline
\end{tabular}

Note: $* P<0.05, * * P<0.01, * * * P<0.001$, compared with day 0 . Abbreviation: CsA, cyclosporine-A. 
A
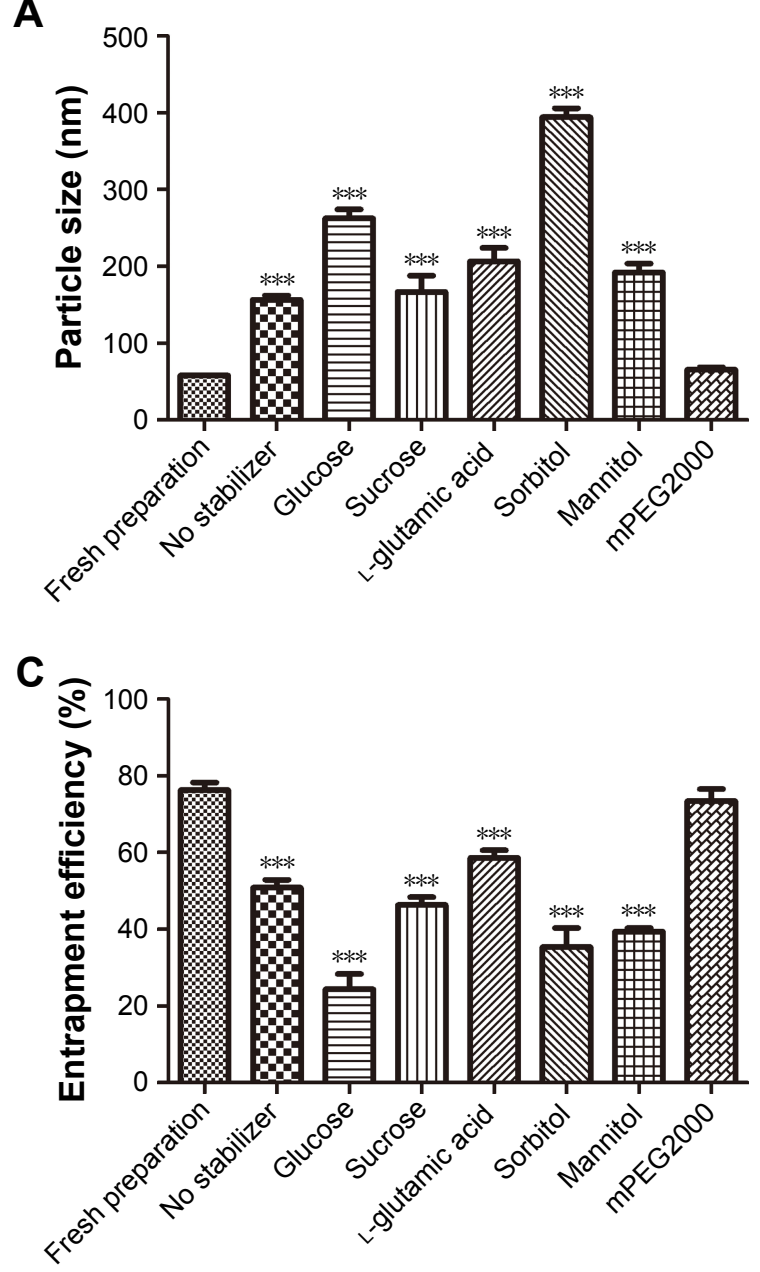

B

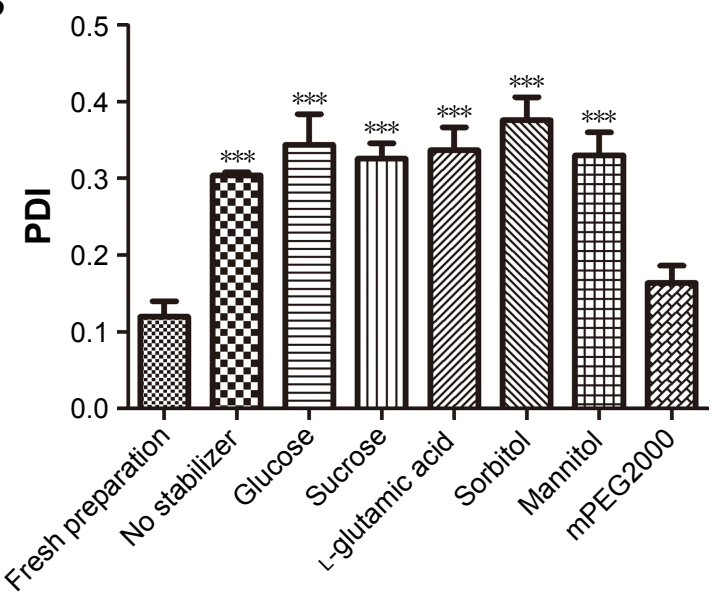

D

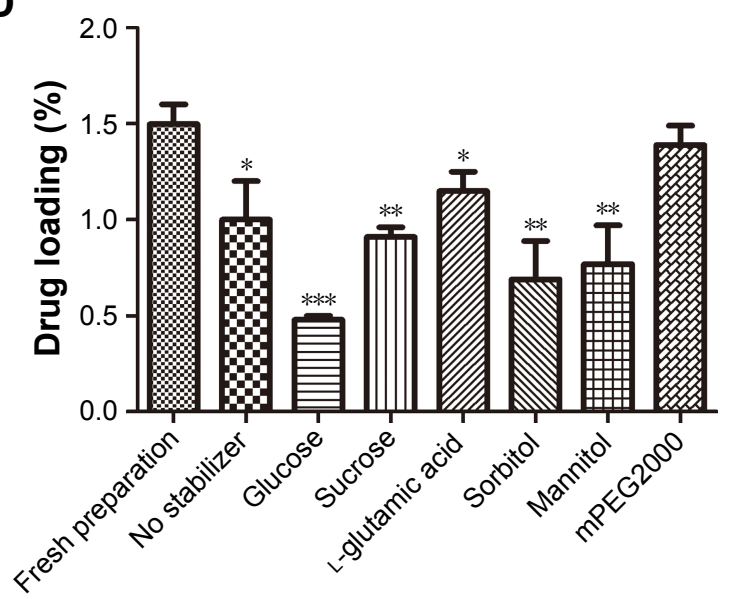

Figure 5 (A) Particle size, (B) PDI, (C) entrapment efficiency, and (D) drug loading of CsA-loaded mPEG-PLA polymeric micelles with different stabilizers. $\mathrm{n}=3$, mean \pm SD. $*$, **, and *** indicate $P<0.05, P<0.01$, and $P<0.001$, respectively, versus fresh preparation.

Abbreviations: CsA, cyclosporine-A; mPEG, methoxy poly(ethylene glycol); PDI, polydispersity index; PLA, poly(lactide).

micelles almost tended to become larger $(P<0.001)$ after lyophilization except for micelles with 5\% mPEG2000. The addition of $5 \%$ mPEG2000 retained the size of the particles and polydispersity index values of the CsA-loaded polymeric micelles remained unchanged. In addition, higher EE\% and DL\% were attained when mPEG2000 was added as compared to the other stabilizers. The greatest decrease in EE\% $(P<0.001)$ and DL\% $(P<0.05)$ was observed when other stabilizers were used in the formulations. From these results, 5\% mPEG2000 was chosen as a stabilizer for lyophilization since it did not change the particle size, EE\%, and DL\% of the CsA polymeric micelles. The result is consistent with the observations of our previous studies. ${ }^{44}$ mPEG2000 consists of PEG chain structural units and has a similar structure with the micelle shell. The addition of mPEG2000 could fill the gap of micelles and micelles filled with PEG chain units. In the process of lyophilization,
mPEG2000 mainly played the role of steric stabilizers to protect the micelles. ${ }^{45}$

\section{Physical stability of CsA micelle lyophilization}

The CsA-loaded mPEG-PLA micelle lyophilized powder was investigated for physical stability under a strong light and high temperature environment. As presented in Table 6, there were no significant changes in the particle size and $\mathrm{EE} \%$ of the lyophilized product, indicating that the lyophilized powders were stable under severe reaction conditions $\left(40^{\circ} \mathrm{C}\right.$, $60^{\circ} \mathrm{C}$, or light with $4,500 \pm 500 \mathrm{Lx}$ for 10 days). Furthermore, the results showed that there were no significant differences in the diameter and $\mathrm{EE} \%$ of the fresh micelles solution and lyophilized formulations $(P>0.05)$. This indicated that reconstitution of the lyophilized powder is suitable for clinical applications. Based on the above results, the CsA micelle 
Table 6 Variations in CsA micelle lyophilized powder $(n=3$, mean \pm SD)

\begin{tabular}{l|l|l|l}
\hline \multirow{2}{*}{$\begin{array}{l}\text { Time } \\
\text { (days) }\end{array}$} & \multirow{2}{*}{$\begin{array}{l}\text { Environmental } \\
\text { conditions }\end{array}$} & \multicolumn{2}{|l}{ Characteristics } \\
\cline { 3 - 4 } & & $\begin{array}{l}\text { Particle } \\
\text { size }(\mathbf{n m})\end{array}$ & $\begin{array}{l}\text { Entrapment } \\
\text { efficiency }(\%)\end{array}$ \\
\hline 0 & $25^{\circ} \mathrm{C}$ & $57.00 \pm 0.65$ & $98.51 \pm 1.40$ \\
5 & $40^{\circ} \mathrm{C}$ & $59.10 \pm 2.88$ & $97.63 \pm 0.68$ \\
5 & $60^{\circ} \mathrm{C}$ & $60.00 \pm 1.56$ & $96.40 \pm 2.86$ \\
5 & Light & $59.03 \pm 3.59$ & $98.40 \pm 0.53$ \\
10 & $40^{\circ} \mathrm{C}$ & $60.13 \pm 3.07$ & $96.03 \pm 0.97$ \\
10 & $60^{\circ} \mathrm{C}$ & $60.77 \pm 3.25$ & $95.73 \pm 3.02$ \\
10 & Light & $61.63 \pm 3.21$ & $95.27 \pm 1.86$ \\
\hline
\end{tabular}

Abbreviation: CsA, cyclosporine-A.

lyophilized formulations were stable and favor long-term preservation.

\section{In vitro release study}

The in vitro release profiles of free $\mathrm{CsA}$ and $\mathrm{CsA}$ from $\mathrm{mPEG}-$ PLA micelles in $0.25 \%$ SLS solution are shown in Figure 6. As can be seen, free CsA was released up to $91.92 \%$ after 1 hour. CsA loaded in mPEG-PLA micelles presented a twostep release pattern without a burst effect, demonstrating an initial rapid release period at 36 hours, in which about $73.08 \%$ CsA was released, followed by a prolonged release of up to 92 hours reaching a cumulative release of CsA close to $89.23 \%$. Due to the high hydrophobicity of CsA, it was encapsulated into the core and was restricted for drug release from the kernels, which resulted in a sustained release. ${ }^{39}$

It should be noted that the release of CsA from the mPEG-PLA micelles followed more than one type of

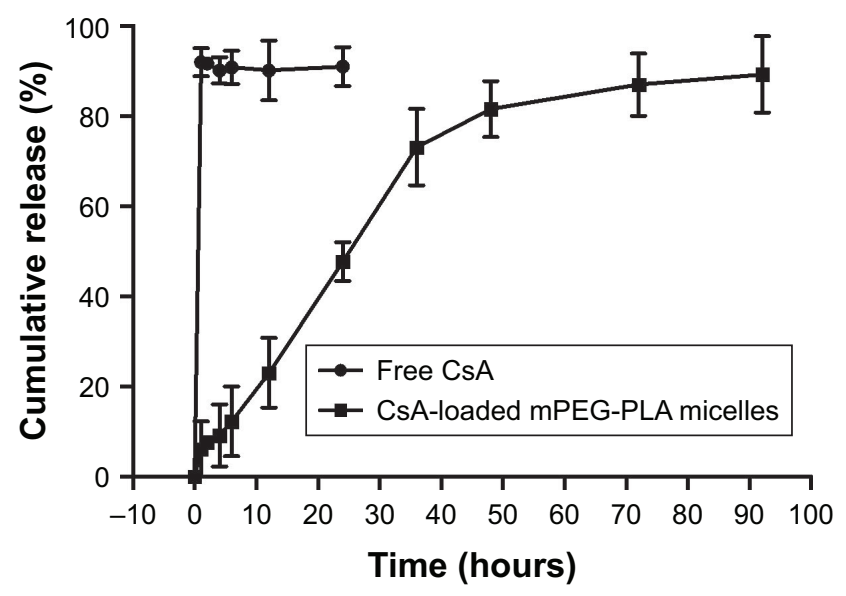

Figure 6 In vitro release profile of free CsA and CsA-loaded mPEG-PLA micelles in $0.25 \%$ SLS solution $(n=3$, mean \pm SD).

Abbreviations: CsA, cyclosporine-A; mPEG, methoxy poly(ethylene glycol); PLA, poly(lactide); SLS, sodium lauryl sulfate. mechanism, including diffusion of $\mathrm{CsA}$ and the dissociation and degradation of mPEG-PLA micelles. The results of the release studies were fitted with some kinetic models (zeroorder, first-order, Higuchi's, Hixson-Crowell's, Weibull's, Peppas-Sahlin's, and Korsmeyer-Peppas kinetic equations) to investigate the CsA release behavior. ${ }^{46-49}$ As shown in Table 7, the comparison of $R^{2}$ values for the different kinetic equations indicated that the best agreement of fitting was achieved with the Peppas-Sahlin equation $\left(R^{2}=0.9917\right)$. The results suggested that the $\mathrm{mPEG}$-PLA micelles may provide prolonged release of CsA.

\section{In vitro cytotoxicity}

The survival rate of the HCE-2 cells declined in a dosedependent manner $(P<0.001)$ (Figure 7A). CsA showed a significant level of cytotoxicity at concentrations up to $10 \mu \mathrm{g} / \mathrm{mL}$ after 24 hours of incubation. Cell viability at 0.1 and $1 \mu \mathrm{g} / \mathrm{mL}$ of free CsA was significantly higher $(P<0.001)$ in comparison to the other concentrations of free CsA $(10,50,100$, and $200 \mu \mathrm{g} / \mathrm{mL})$. Similarly, the cytotoxicity levels were increased by increasing the incubation time.

Figure 7B and $\mathrm{C}$ shows the cytotoxicity level of blank mPEG-PLA micelles at 24 and 48 hours, respectively. The results showed that about $80 \%$ of the cells were alive even at higher concentrations, ie, $5 \mathrm{mg} / \mathrm{mL}$ of blank mPEG-PLA.

The cytotoxicity results of CsA-loaded mPEG-PLA micelles are depicted in Figure 7D and E. The survival rate of cells decreased with an increase in incubation time and micelle concentration. A significant difference in survival rate for the cells treated with mPEG-PLA (60:40) and mPEGPLA (50:50) micelles was observed $(P<0.01)$. mPEG-PLA $(50: 50)$ showed lower toxicity in comparison to mPEG-PLA $(60: 40)$ micelles. This difference in cytotoxicity is postulated due to the difference in the relative MW of the hydrophobic PLA segment. An increase in the amount of hydrophobic segments would have a higher affinity to form aggregations at lower CMCs. In this way, the self-assembled micelles became more stable and reduced cytotoxicity.

\section{In vivo eye irritation test}

The biocompatibility of mPEG-PLA micelles with different weight ratios was investigated in the eye balls of rabbits. After 3 weeks study, ocular tissues (cornea, conjunctiva, sclera, and iris) of the rabbits were collected for histopathological analysis. Histopathological evaluation showed all the signs representative of control eyes similar to the tests above (Figure 8A). mPEG-PLA micelles with different weight 
Table 7 CsA-loaded mPEG-PLA micelles release in vitro

\begin{tabular}{|c|c|c|c|}
\hline \multirow[t]{2}{*}{ Model } & \multicolumn{3}{|l|}{ CsA micelles } \\
\hline & Equation & $R^{2}$ & $R_{\text {adjusted }}^{2}$ \\
\hline Zero-order & $\mathrm{Q}=1.252 \mathrm{t}$ & 0.8197 & 0.8197 \\
\hline First-order & $Q=100[1-\exp (-0.03 t)]$ & 0.9851 & 0.9851 \\
\hline Higuchi & $\mathrm{Q}=10.020 \mathrm{t}^{0.5}$ & 0.9378 & 0.9378 \\
\hline Hixson-Crowell & $\mathrm{Q}=100\left[\mathrm{I}-(\mathrm{I}-0.008 * \mathrm{t})^{3}\right]$ & 0.9818 & 0.9817 \\
\hline Weibull & $\mathrm{Q}=100\left\{\mathrm{I}-\exp \left[-\left((\mathrm{t}+0.896)^{1.183}\right) / 65.155\right]\right\}$ & 0.9879 & 0.9849 \\
\hline Peppas-Sahlin & $\mathrm{Q}=2.419 \mathrm{t}^{1.005}-0.016 \mathrm{t}^{2.01}$ & 0.9917 & 0.9916 \\
\hline Korsmeyer-Peppas & $\mathrm{Q}=7.2 \mathrm{t}^{0.584}$ & 0.9475 & 0.9417 \\
\hline
\end{tabular}

Abbreviations: CsA, cyclosporine-A; mPEG, methoxy poly(ethylene glycol); PLA, poly(lactide).

ratios-treated eyes and their corresponding contralateral control eyes demonstrated anterior eye segments and normal ocular surface structures with preserved morphology and architecture. After 3 weeks administration, there was no inflammatory response (inflammatory cells infiltration, edema, and atrophy) observed on the cornea, conjunctiva, sclera, and iris in the test groups, which indicated that
mPEG-PLA micelles with different weight ratios showed no irritation in the in vivo test.

\section{Transcorneal mechanism study of mPEG-} PLA micelles

The mPEG-PLA micelle transcorneal mechanism was studied after the instillation of a fluorescein aqueous solution
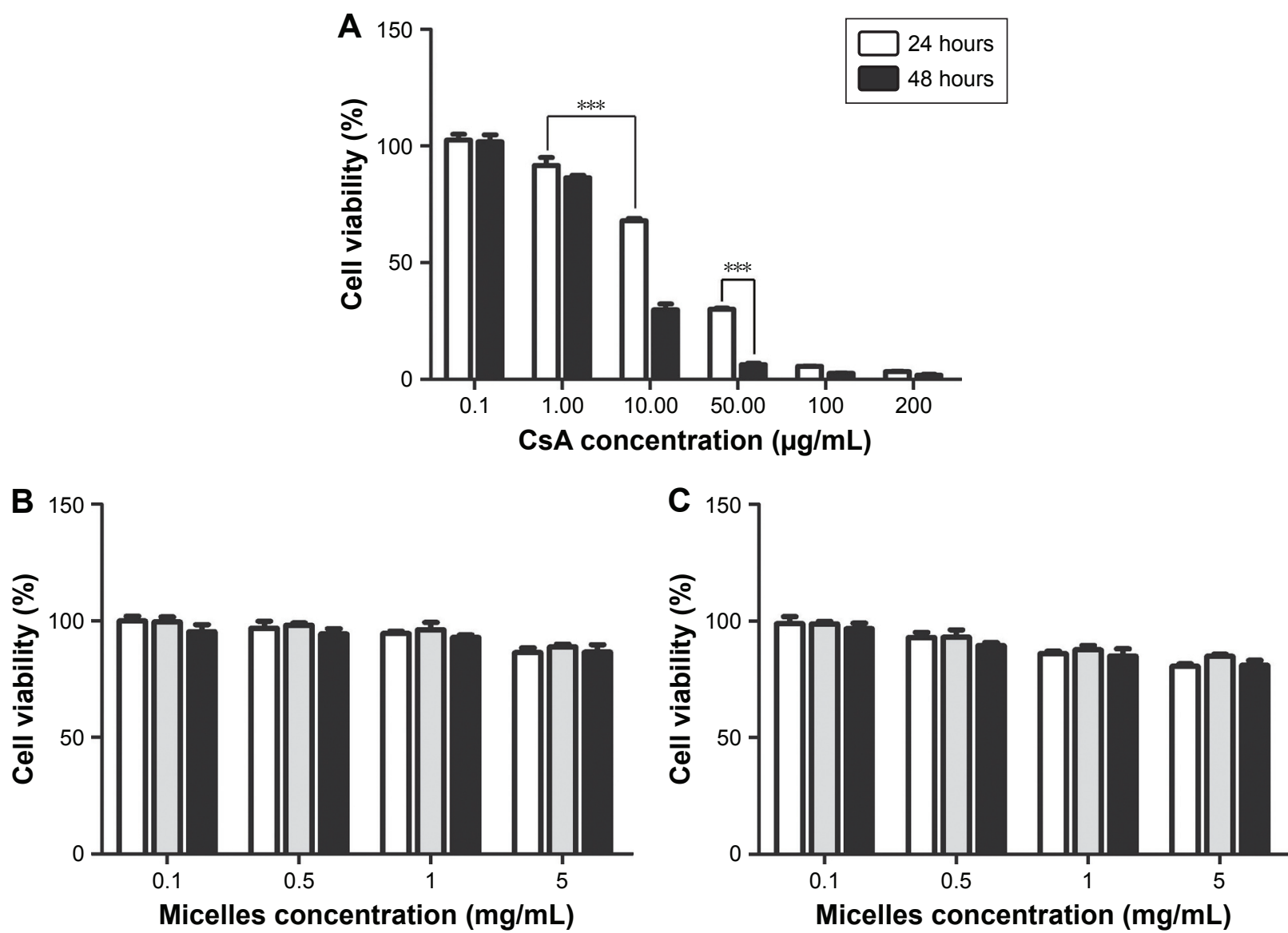

$\square$ mPEG-PLA (60:40) $\square$ mPEG-PLA (50:50) $\square$ mPEG-PLA (40:60)

Figure 7 (Continued) 

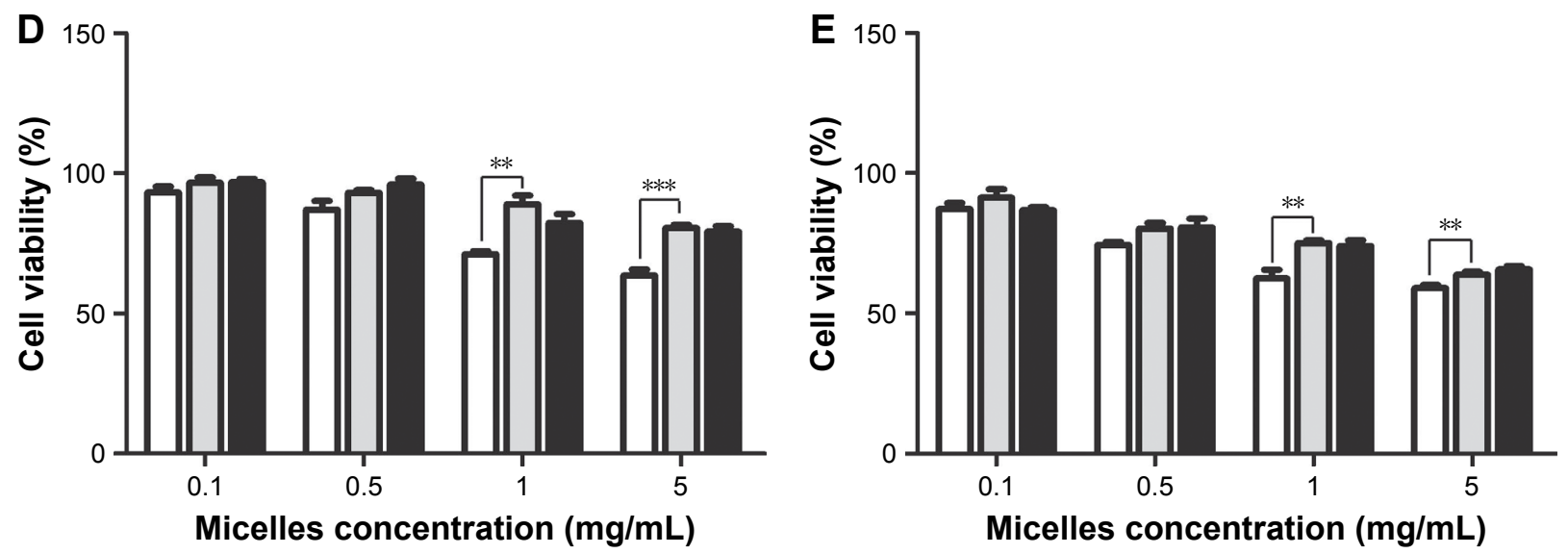

$\square$ mPEG-PLA (60:40) $\square$ mPEG-PLA (50:50) $\square$ mPEG-PLA (40:60)

Figure 7 (A) Cytotoxicity of free CsA. Cell viability of blank mPEG-PLA micelles at (B) 24 hours and (C) 48 hours. Cell viability of CsA-loaded mPEG-PLA micelles at (D) 24 hours and (E) 48 hours. $n=6$, mean \pm SD. $* *$ and $* * *$ represent $P<0.01$ and $P<0.00$ I, respectively.

Abbreviations: CsA, cyclosporine-A; mPEG, methoxy poly(ethylene glycol); PLA, poly(lactide).
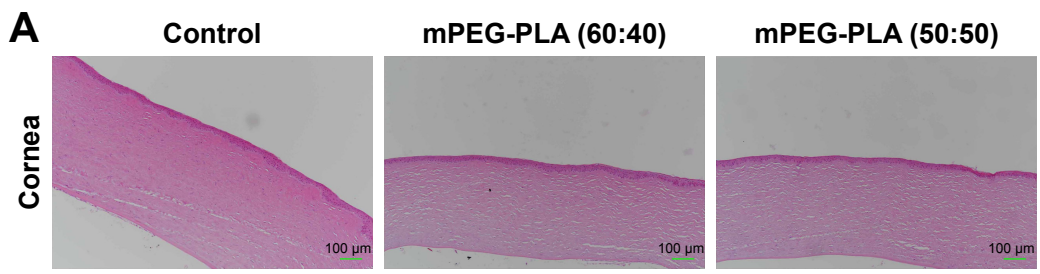

MPEG-PLA (40:60)
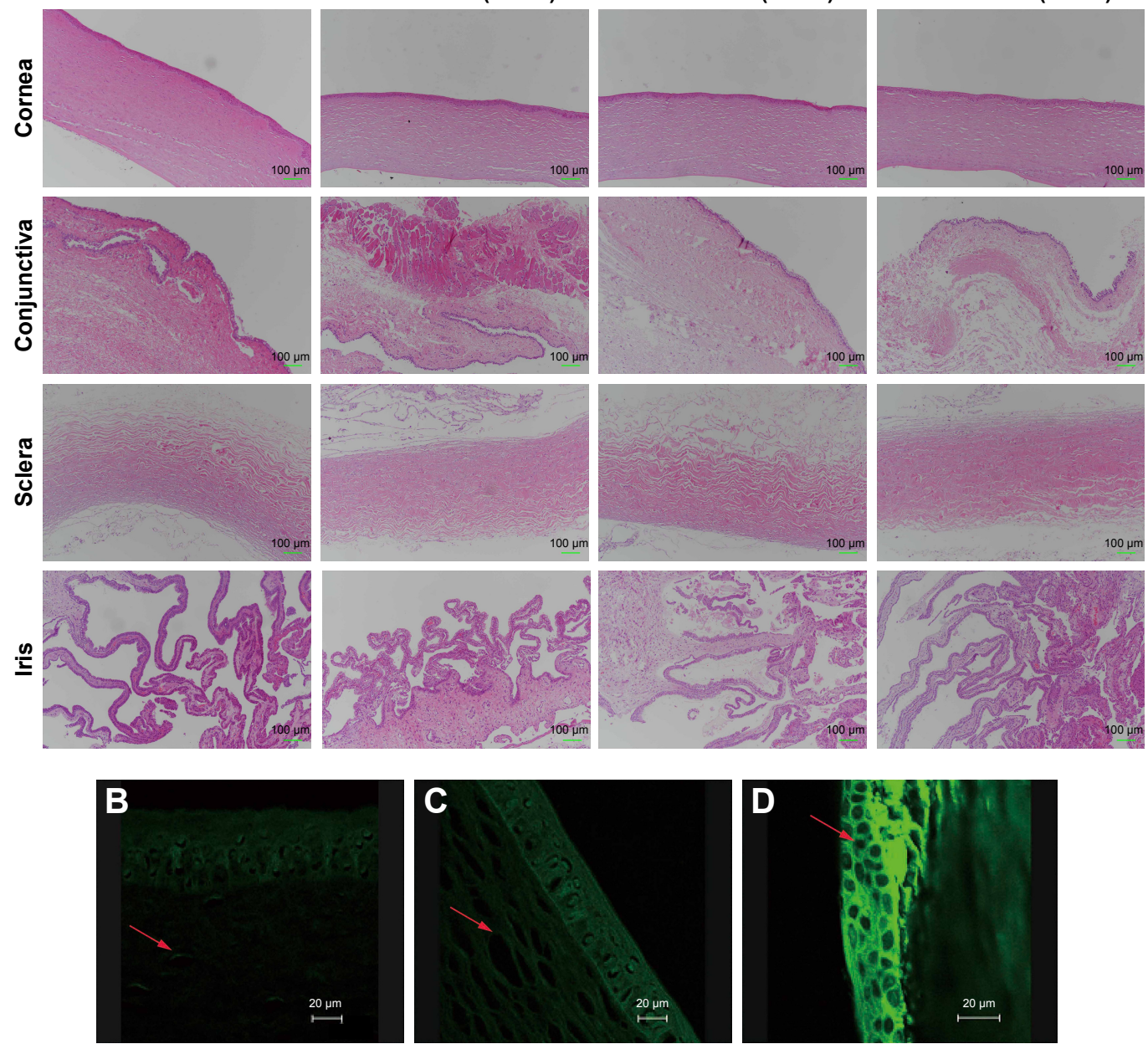

Figure 8 (A) Histology of cornea, conjunctiva, sclera, and iris after instilling mPEG-PLA micelles with different weight ratios at 3 weeks. Sections were embedded in paraffin and stained with H\&E. Scale bars represent $100 \mu \mathrm{m}$. Confocal fluorescence images of the rabbit eye after 2 hours of instillation of (B) fluorescein solution, (C) fluorescein polymeric micelles, and (D) fluorescein polymeric micelles with $0.25 \%$ EDTA. Scale bars represent $20 \mu \mathrm{m}$. Arrows indicate the cells.

Abbreviations: mPEG, methoxy poly(ethylene glycol); PLA, poly(lactide). 
and fluorescein micellar solution in the conjunctival sac of rabbits for 2 hours. The distribution of fluorescein in the cornea was observed by confocal laser scanning microscopy. The fluorescence intensity of the micelle solution in the cornea was stronger than that of the fluorescein aqueous solution, as illustrated in Figure $8 \mathrm{~B}$ and C. It is possible that the micelles accumulated in the tear film layer, thereby being retained in the eye, and more fluorescein entered the cornea; so, the micelle solution had a higher fluorescence intensity in the cornea. ${ }^{50}$ Whether it was the fluorescein aqueous solution or micelle solution, the corneal epithelium showed stronger fluorescence intensity than the stroma because the epithelial cells hindered the entry of fluorescein in the cornea, hence resulting in a decline in the retention effect.

Figure 8D shows the distribution of fluorescence in the epithelial cells at 2 hours after administration of the micelle solution along with $0.25 \%$ EDTA. It can be observed that the intercellular space of epithelial cells showed stronger fluorescent signals than the epithelial cells. It is well known that $\mathrm{Ca}^{2+}$ ions have an important role in maintaining the paracellular permeability in epithelial cell monolayers by modulating tight junctions. ${ }^{51}$ EDTA depletes $\mathrm{Ca}^{2+}$ in the extracellular space including the tight junction region and activates protein kinase $\mathrm{C}$, resulting in paracellular permeability. ${ }^{35}$ It was clear that the fluorescein mainly passed through the corneal epithelial cells through the paracellular pathways.

\section{Conclusion}

The present study reported the formulation and physicochemical characterization of lyophilized CsA-loaded mPEG-PLA micelles for ophthalmic preparations. Uniform design was used to obtain the optimal formulation which was composed of $2 \%$ HPMC, $0.01 \%$ EDTA-2Na, and $0.37 \%$ drug and polymer ratio. These CsA-loaded $\mathrm{mPEG}-\mathrm{PLA}$ micelles resulted in a spherical core-shell structure with a homogeneous size distribution, as confirmed by TEM. Stability studies of the CsA micelle solution and lyophilized powder were carried out to determine the long storage conditions of the formulation. The in vitro release profile study indicated a sustained release pattern of CsA from the micelles. The mechanism study showed that the developed mPEG-PLA micelles mainly absorbed via a paracellular pathway in corneal epithelial cells. Conclusively, the mPEG-PLA diblock polymer is a safe and promising carrier to further develop for improved ocular therapy.

\section{Acknowledgments}

This work was supported by the Ministry of Science and Technology of China (2017ZX09101001-005-003), the National Natural Science Foundation of China (81501579 and
81673364), the Natural Science Foundation of Jiangsu Province (BK20150702), the Science and Technology Development Fund of Nanjing Medical University (2016NJMU105), the Priority Academic Program Development of Jiangsu Higher Education Institutions and the Postgraduate Research and Practice Innovation Program of Jiangsu Province (KYCX17_0674), China Postdoctoral Science Foundation (2017M610309), and the Training Project of Jiangsu University for Young Key Teachers (5521290003).

\section{Disclosure}

The authors report no conflicts of interest in this work.

\section{References}

1. Gupta V, Sahu PK. Topical cyclosporin A in the management of vernal keratoconjunctivitis. Eye (Lond). 2001;15(Pt 1):39-41.

2. Moore CP, McHugh JB, Thorne JG, Phillips TE. Effect of cyclosporine on conjunctival mucin in a canine keratoconjunctivitis sicca model. Invest Ophthalmol Vis Sci. 2001;42(3):653-659.

3. Waldmeier PC, Zimmermann K, Qian T, Tintelnot-Blomley M, Lemasters JJ. Cyclophilin D as a drug target. Curr Med Chem. 2003; 10(16):1485-1506.

4. Ismailos G, Reppas C, Dressman JB, Macheras P. Unusual solubility behaviour of cyclosporin A in aqueous media. $J$ Pharm Pharmacol. 1991;43(4):287-289.

5. Furrer P, Mayer JM, Plazonnet B, Gurny R. Ocular tolerance of preservatives on the murine cornea. Eur J Pharm Biopharm. 1999;47(2):105-112.

6. Adriaens E, Dierckens K, Bauters TG, et al. The mucosal toxicity of different benzalkonium chloride analogues evaluated with an alternative test using slugs. Pharm Res. 2001;18(7):937-942.

7. Monti D, Chetoni P, Burgalassi S, Najarro M, Saettone MF. Increased corneal hydration induced by potential ocular penetration enhancers: assessment by differential scanning calorimetry (DSC) and by desiccation. Int J Pharm. 2002;232(1-2):139-147.

8. Gelderblom H, Verweij J, Nooter K, Sparreboom A. Cremophor EL: the drawbacks and advantages of vehicle selection for drug formulation. Eur J Cancer. 2001;37(13):1590-1598.

9. Lallemand F, Schmitt M, Bourges JL, Gurny R, Benita S, Garrigue JS. Cyclosporine A delivery to the eye: A comprehensive review of academic and industrial efforts. Eur J Pharm Biopharm. 2017;117:14-28.

10. Lallemand F, Daull P, Benita S, Buggage R, Garrigue JS. Successfully improving ocular drug delivery using the cationic nanoemulsion, novasorb. J Drug Deliv. 2012;2012:604204.

11. Drugs.com. Restasis [2017]. Available from: https://www.drugs.com/ pro/restasis.html. Accessed May 5, 2018.

12. European Medicines Agency; Science Medicines Health. Public assessment report: Ikervis [2015]. Available from: https://www.google.co.nz/ search?q=ikervis-epar-public-assessment-report_en\&rlz=1C1GCEU_ enNZ821 NZ821\&oq=ikervis-epar-public-assessment-report_en\&aq $\mathrm{s}=$ chrome..69i57.447j0j4\&sourceid $=$ chrome $\& \mathrm{ie}=\mathrm{UTF}-8 \#$. Accessed May 5, 2018.

13. van der Bijl P, van Eyk AD, Meyer D. Effects of three penetration enhancers on transcorneal permeation of cyclosporine. Cornea. 2001; 20(5):505-508.

14. Ludwig A. The use of mucoadhesive polymers in ocular drug delivery. Adv Drug Deliv Rev. 2005;57(11):1595-1639.

15. Sintzel MB, Bernatchez SF, Tabatabay C, Gurny R. Biomaterials in ophthalmic drug delivery. Eur J Pharm Biopharm. 1996;42:358-374.

16. Gavini E, Chetoni P, Cossu M, Alvarez MG, Saettone MF, Giunchedi P. PLGA microspheres for the ocular delivery of a peptide drug, vancomycin using emulsification/spray-drying as the preparation method: in vitro/in vivo studies. Eur J Pharm Biopharm. 2004;57(2):207-212. 
17. Calvo P, Vila-Jato JL, Alonso MJ. Comparative in vitro evaluation of several colloidal systems, nanoparticles, nanocapsules, and nanoemulsions, as ocular drug carriers. J Pharm Sci. 1996;85(5):530-536.

18. Milani JK, Pleyer U, Dukes A, et al. Prolongation of corneal allograft survival with liposome-encapsulated cyclosporine in the rat eye. Ophthalmology. 1993;100(6):890-896.

19. Kuwano M, Ibuki H, Morikawa N, Ota A, Kawashima Y. Cyclosporine A formulation affects its ocular distribution in rabbits. Pharm Res. 2002;19(1):108-111.

20. Snibson GR, Greaves JL, Soper ND, Prydal JI, Wilson CG, Bron AJ. Precorneal residence times of sodium hyaluronate solutions studied by quantitative gamma scintigraphy. Eye (Lond). 1990;4(Pt 4):594-602.

21. Lang JC. Ocular drug delivery conventional ocular formulations. Adv Drug Deliv Rev. 1995;16(1):39-43.

22. Prausnitz MR, Noonan JS. Permeability of cornea, sclera, and conjunctiva: a literature analysis for drug delivery to the eye. J Pharm Sci. 1998;87(12):1479-1488.

23. Yokoi N, Komuro A. Non-invasive methods of assessing the tear film. Exp Eye Res. 2004;78(3):399-407.

24. Mondon K, Zeisser-Labouèbe M, Gurny R, Möller M. Novel cyclosporin A formulations using MPEG-hexyl-substituted polylactide micelles: a suitability study. Eur J Pharm Biopharm. 2011;77(1):56-65.

25. Nishiyama N, Kataoka K. Nanostructured devices based on block copolymer assemblies for drug delivery: designing structures for enhanced drug function. In: Satchi-Fainaro R, Duncan R, editors. Polymer Therapeutics II. Advances in Polymer Science. Berlin, Heidelberg: Springer; 2006.

26. Lavasanifar A, Samuel J, Kwon GS. Poly(ethylene oxide)-blockpoly(L-amino acid) micelles for drug delivery. Adv Drug Deliv Rev. 2002;54(2):169-190.

27. Lin W-J, Juang LW, Wang CL, Chen YC, Lin CC, Chang KL. Pegylated Polyester Polymeric Micelles as a Nano-carrier: Synthesis, Characterization, Degradation, and Biodistribution. J Exp Clin Med. 2010;2(1):4-10.

28. Adami R, Liparoti S, Izzo L, Pappalardo D, Reverchon E. PLA-PEG copolymers micronization by supercritical assisted atomization. J Supercrit Fluids. 2012;72(72):15-21.

29. Chen J, Xing MMQ, Zhong W. Degradable micelles based on hydrolytically degradable amphiphilic graft copolymers for doxorubicin delivery. Polymer. 2011;52(4):933-941.

30. Dong Y, Feng SS. In vitro and in vivo evaluation of methoxy polyethylene glycol-polylactide (MPEG-PLA) nanoparticles for small-molecule drug chemotherapy. Biomaterials. 2007;28(28):4154-4160.

31. Layre AM, Couvreur P, Richard J, Requier D, Eddine Ghermani N, Gref R. Freeze-drying of composite core-shell nanoparticles. Drug Dev Ind Pharm. 2006;32(7):839-846.

32. Wang Y, Huang L, Shen Y, et al. Electrostatic interactions between polyglutamic acid and polylysine yields stable polyion complex micelles for deoxypodophyllotoxin delivery. Int J Nanomedicine. 2017;12: 7963-7977.

33. Li J, Huo M, Wang J, et al. Redox-sensitive micelles self-assembled from amphiphilic hyaluronic acid-deoxycholic acid conjugates for targeted intracellular delivery of paclitaxel. Biomaterials. 2012;33(7): $2310-2320$.
34. Brocks DR, Betageri GV. Enhanced oral absorption of halofantrine enantiomers after encapsulation in a proliposomal formulation. J Pharm Pharmacol. 2002;54(8):1049-1053.

35. Tomita M, Hayashi M, Awazu S. Absorption-enhancing mechanism of EDTA, caprate, and decanoylcarnitine in Caco-2 cells. J Pharm Sci. 1996;85(6):608-611.

36. Shi Y, Huang W, Liang R, et al. Improvement of in vivo efficacy of recombinant human erythropoietin by encapsulation in PEG-PLA micelle. Int J Nanomedicine. 2013;8:1-11.

37. Elsabahy M, Dufresne M, Leroux JC. Polymeric micelles as versatile carriers for drugs and nucleic acids delivery. In: Torchilin V, Amiji M, editors. Handbook of Materials and Nanomedicine. Hackensack, NJ: Pan Stanford Publishing; 2010.

38. Bakshi MS, Sachar S. Influence of temperature on the mixed micelles of Pluronic F127 and P103 with dimethylene-bis(dodecyldimethylammonium bromide. J Colloid Interface Sci. 2006; 296(1):309-315.

39. Huang S, Yu X, Yang L, et al. The efficacy of nimodipine drug delivery using mPEG-PLA micelles and mPEG-PLA/TPGS mixed micelles. Eur J Pharm Sci. 2014;63:187-198.

40. Gou M, Zheng X, Men K, et al. Self-assembled hydrophobic honokiol loaded MPEG-PCL diblock copolymer micelles. Pharm Res. 2009;26(9): 2164-2173.

41. Husek A. High-performance liquid chromatographic analysis of cyclosporin A and its oral solutions. J Chromatogr A. 1997;759(1-2): 217-224.

42. Hu L, Gao W, Zhang J, Pan H, Liu H. Development of a new coenzyme Q10 (CoQ10) mixed micelle with high stability: Based on the thermodynamics of cloud point. J Mol Liq. 2017;242:16-23.

43. Kang H, Cha KH, Cho W, et al. Cyclosporine Amicellar delivery system for dry eyes. Int J Nanomedicine. 2016;11:2921-2933.

44. Yu Y, Chen D, Li Y, Yang W, Tu J, Shen Y. Improving the topical ocular pharmacokinetics of lyophilized cyclosporine A-loaded micelles: formulation, in vitro and in vivo studies. Drug Deliv. 2018;25(1):888-899.

45. Heald CR, Stolnik S, de Matteis C, et al. Self-consistent field modelling of poly(lactic acid)-poly(ethylene glycol) particles. Colloids Surf A Physicochem Eng Asp. 2001;179(1):79-91.

46. Siepmann J, Peppas NA. Modeling of drug release from delivery systems based on hydroxypropyl methylcellulose (HPMC). Adv Drug Deliv Rev. 2001;48(2-3):139-157.

47. Dash S, Murthy PN, Nath L, Chowdhury P. Kinetic modeling on drug release from controlled drug delivery systems. Acta Pol Pharm. 2010; 67(3):217-223

48. Tığlı Aydın RS, Pulat M. 5-Fluorouracil Encapsulated Chitosan Nanoparticles for pH-Stimulated Drug Delivery: Evaluation of Controlled Release Kinetics. J Nanomater. 2012 (11):2817-2827.

49. Mehta SK, Jindal N. Mixed micelles of Lecithin-Tyloxapol as pharmaceutical nanocarriers for anti-tubercular drug delivery. Colloids Surf B Biointerfaces. 2013;110(10):419-425.

50. Schechter BA, Katz RS, Friedman LS. Efficacy of topical cyclosporine for the treatment of ocular rosacea. Adv Ther. 2009;26(6):651-659.

51. Zhao S, Dai W, He B, et al. Monitoring the transport of polymeric micelles across MDCK cell monolayer and exploring related mechanisms. J Control Release. 2012;158(3):413-423.
International Journal of Nanomedicine

\section{Publish your work in this journal}

The International Journal of Nanomedicine is an international, peerreviewed journal focusing on the application of nanotechnology in diagnostics, therapeutics, and drug delivery systems throughout the biomedical field. This journal is indexed on PubMed Central, MedLine, CAS, SciSearch ${ }^{\circledR}$, Current Contents ${ }^{\circledR} /$ Clinical Medicine,
Dovepress

Journal Citation Reports/Science Edition, EMBase, Scopus and the Elsevier Bibliographic databases. The manuscript management system is completely online and includes a very quick and fair peer-review system, which is all easy to use. Visit http://www.dovepress.com/ testimonials.php to read real quotes from published authors. 